San Jose State University

SJSU ScholarWorks

Master's Theses

Master's Theses and Graduate Research

1991

\title{
Exploring the cognitive structures underlying young children's interpretation and handling of the Loma Prieta earthquake
}

Jane Farish

San Jose State University

Follow this and additional works at: https://scholarworks.sjsu.edu/etd_theses

\section{Recommended Citation}

Farish, Jane, "Exploring the cognitive structures underlying young children's interpretation and handling of the Loma Prieta earthquake" (1991). Master's Theses. 114.

DOI: https://doi.org/10.31979/etd.7anc-8swn

https://scholarworks.sjsu.edu/etd_theses/114

This Thesis is brought to you for free and open access by the Master's Theses and Graduate Research at SJSU ScholarWorks. It has been accepted for inclusion in Master's Theses by an authorized administrator of SJSU ScholarWorks. For more information, please contact scholarworks@sjsu.edu. 


\section{INFORMATION TO USERS}

This manuscript has been reproduced from the microfilm master. UMI films the text directly from the original or copy submitted. Thus, some thesis and dissertation copies are in typewriter face, while others may be from any type of computer printer.

The quality of this reproduction is dependent upon the quality of the copy submitted. Broken or indistinct print, colored or poor quality illustrations and photographs, print bleedthrough, substandard margins, and improper alignment can adversely affect reproduction.

In the unlikely event that the author did not send UMI a complete manuscript and there are missing pages, these will be noted. Also, if unauthorized copyright material had to be removed, a note will indicate the deletion.

Oversize materials (e.g., maps, drawings, charts) are reproduced by sectioning the original, beginning at the upper left-hand corner and continuing from left to right in equal sections with small overlaps. Each original is also photographed in one exposure and is included in reduced form at the back of the book.

Photographs included in the original manuscript have been reproduced xerographically in this copy. Higher quality $6^{\prime \prime} \times 9^{\prime \prime}$ black and white photographic prints are available for any photographs or illustrations appearing in this copy for an additional charge. Contact UMI directly to order.

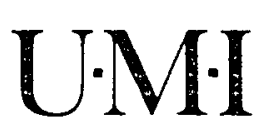

University Microfilms International

A Bell \& Howell Information Company 
Order Number 1344260

Exploring the cognitive structures underlying young children's interpretation and handling of the Loma Prieta earthquake

\author{
Farish, Jane M., M.A.
}

San Jose State University, 1991

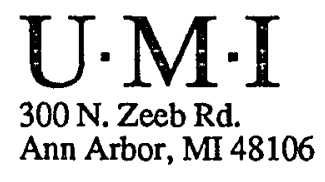





\title{
EXPLORING THE COGNITIVE STRUCTURES UNDERLYING YOUNG CHILDREN'S INTERPRETATION AND HANDLING OF \\ THE LOMA PRIETA EARTHQUAKE
}

\author{
A Thesis \\ Presented to \\ the Faculty of the Division of Teacher Education \\ San Jose State University
}

\author{
In Partial Fulfillment \\ of the Requirements for the Degree \\ Master of Arts
}

by
Jane Farish
May, 1991 
APPROVED FOR THE DIVISION OF TEACHER EDUCATION

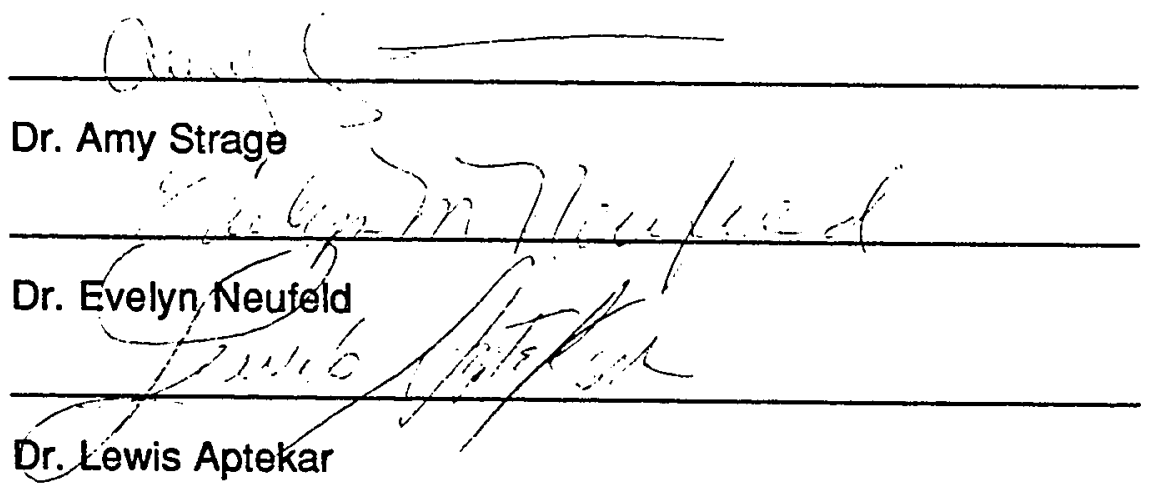

APPROVED FOR THE UNIVERSITY

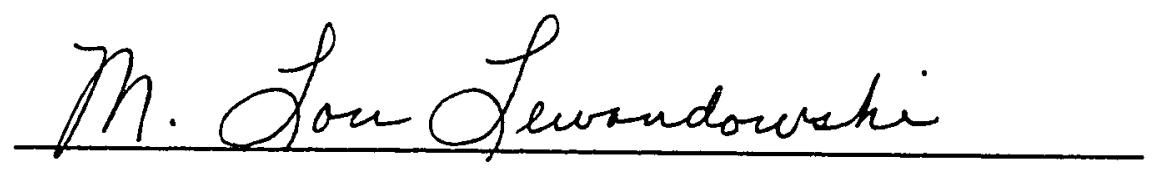




\section{ABSTRACT \\ EXPLORING THE COGNITIVE \\ STRUCTURES UNDERLYING YOUNG CHILDREN'S \\ INTERPRETATION AND HANDLING OFTHE LOMA PRIETA EARTHQUAKE}

By Jane Farish

The reactions of 106 preschool-aged children (mean age $=50.1$ months) to the Loma Prieta earthquake were studied to examine the affective and cognitive reactions of young children to a natural disaster. Information was obtained through a parent questionnaire. Results showed that, in the month following the earthquake, over $40 \%$ of the subjects experienced some form of affective distress. Girls experienced a more intense reaction than boys, and children aged 60 months and older were more upset than younger ones. Subjects' verbatim responses to questions on the causes and effects of earthquakes confirmed that, at the preoperational level, concepts of causality are limited. Responses displayed identifiable characteristics of preoperational thought including egocentrism, animism, centration, transductive reasoning, and magical thinking. Results showed the whereabouts of children at the time of the earthquake, the emotional reaction of their caretakers, and the amount of damage at their homes, predicted the intensity of their reaction. 


\section{ACKNOWLEDGEMENTS}

I would like to express my appreciation and sincere thanks to Dr. Amy Strage for her valuable assistance and time, and for her enthusiasm for my project. I would also like to thank Dr. Evelyn Neufeld and Dr. Lewis Aptekar for the sharing of their knowledge, and for their helpful suggestions.

My gratitude is also extended to Ann Harding, Janet Harford, and Tinka Niedermier for their advice and support, and to Renee Euchner who facilitated the testing of the questionnaire.

A special thank you to Georgina Sutherst for her encouragement and unfailing help in the completion of this thesis. 


\section{TABLE OF CONTENTS}

PAGE

ACKNOWLEDGEMENTS $\ldots \ldots \ldots \ldots \ldots \ldots$ iv

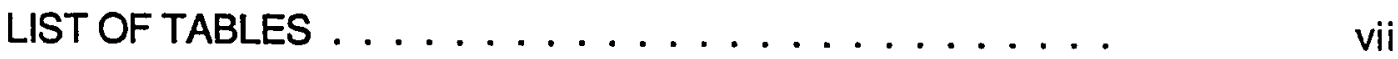

CHAPTER

I. Introduction . . . . . . . . . . . . . . . . 1

Statement of the problem . . . . . . . . . . 2

Purpose of the study . . . . . . . . . . . . 2

Hypotheses and research questions . . . . . . . . 3

Significance of the problem . . . . . . . .

Limitations and delimitations of the study . . . . . . 6

Definition of terms . . . . . . . . . . . 6

II. Review of the literature $\ldots \ldots \ldots \ldots \ldots \ldots \ldots$

Piaget's theory of intellectual development . . . . . . . 9

Cognitive development perspective . . . . . . . . . 14

Preoperational thought . . . . . . . . . . 18

Social cognition . . . . . . . . . . . 26

Stress and coping at the preoperational level . . . . . 30

Young children and disasters . . . . . . . . . . . 34

III. Methodology . . . . . . . . . . . . . . . 39

Introduction . . . . . . . . . . . 39

Research method. . . . . . . . . . . . . 39

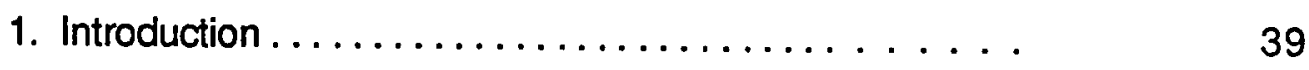


PAGE

2. Research design ............... 40

3. Population and sampling $\ldots \ldots \ldots \ldots$

4.Data Collection . . . . . . . . . . . . 41

4.1 Instrumentation and tools . . . . . . . . . . 41

4.2 Data processing and analysis . . . . . . . . . 43

IV. Results and Discussion . . . . . . . . . . . . . . 47

Hypothesis I. . . . . . . . . . . . . . . 47

Hypothesis II . . . . . . . . . . . . . . 50

Hypothesis III . . . . . . . . . . . . . .

Hypothesis IV . . . . . . . . . . . . . . . . 59

V. Conclusions and recommendations . . . . . . . . 64

Summary of results $\ldots \ldots \ldots \ldots \ldots \ldots \ldots$

Discussion of findings. . . . . . . . 68

Recommendations for further research . . . . . . . . . 72

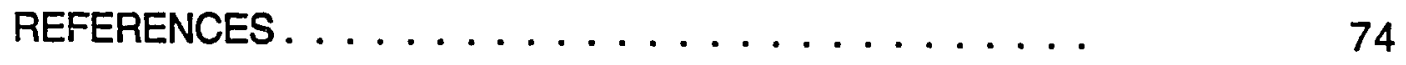

TABLES . . . . . . . . . . . . . . . 78

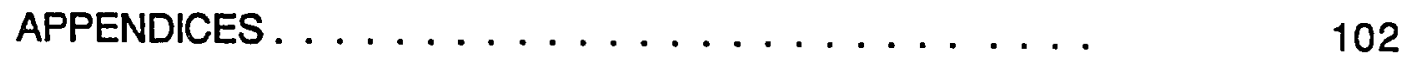

APPENDIX A: Cover letters and Questionnaire . . . . 103

APPENDIX B: Anecdotal Material, Part II, $1 \ldots \ldots . . .112$

APPENDIX C: Anecdotal Material, Part II, 2 . . . . . . 122

APPENDIX D: Data Used for Calculating Intensity of

Reaction Scores . . . . . . . . . 


\section{LIST OF TABLES}

\section{TABLE}

1. Values Assigned Questionnaire Items to Calculate Intensity of Reaction Scores

2. Summary of Questionnaire Items Used for Data Analysis in Answering Research Questions

3. Distribution of Subjects' Disturbed Sleep Patterns

4. Results of Analysis of Separation Anxieties

5. Comparative Categorization of Subjects' Responses Relating to Causes and Effects of Earthquakes

6. Comparative Analysis of Subjects' Concepts of Earthquake's Location

7. Percentage of Subjects Exhibiting Concerns about a Future Earthquake

8. Sleeping and Eating Disturbances and Separation Anxieties as a Function of Chronological Age

9. Average Intensity of Reaction Scores as a Function of Subjects' Ages

10. Relationship Between Whereabouts of Subjects at Time of the Earthquake and Intensity of Reaction Scores

11. Comparison of Amount of Damage to Subjects' Homes and Intensity of Reaction Scores

12. Comparison of Parents' Emotional Reaction to the Earthquake and their Children's Reaction 


\section{TABLES (continued)}

\section{TABLE}

13. Relationship Between Amount of Earthquake Coverage Viewed on TV and Intensity of Reaction Scores 


\section{CHAPTER ONE \\ Introduction to the Problem}

On October 17, 1989, the Loma Prieta earthquake, which measured 7.1 on the Richter Scale, struck parts of Northern California, including Santa Clara County. Young children's reactions in the days immediately following the earthquake were observed, and a number of statements were recorded which reflected their thoughts and feelings about the event. These observations were the catalyst for this study: the data gathering, the subsequent research and analysis, and the discussion of social cognition and its relationship to intellectual development.

This study was concerned with children in the preoperational stage of intellectual development, which encompasses the preschool years. Although, as language develops, thoughts and feelings can be clarified to a degree through verbal reasoning (Piaget, 1967), the cognitive structures of preoperational children place limits on their understanding of new events that occur in their environment, and influence their understanding of theirl. When the event is a stressful one, such as a natural disaster, this limited understanding can result in anxiety (Lazarus \& Folkman, 1984), and may influence children's ability to cope with the event.

In viewing the acquisition of cognitive concepts, intelligence can be considered to be a form of equilibrium (Piaget, 1950), achieved through the interplay of physical and social experience and the development of new cognitive structures. Concepts are developed, from birth onwards, with each developmental stage of childhood having its own specific cognitive organization to structure experiences to which children are exposed. New knowledge must 
be processed through assimilation and accommodation to fit into children's existing knowledge, and, where there is no prior knowledge, children may invent their own concepts and explanations of an event.

\section{Statement of the Problem}

Major earthquakes are a relatively rare occurrence in the United States of America, and the majority of preschool-aged children do not have knowledge or prior experience of them, or of other natural disasters. Knowledge of the stress of such an event for children in this age group, and of their ability to cope with the event, is limited. Available literature about preschool-aged children's distress and coping mechanisms at the time of an earthquake is based on theory (San Fernando Valley Guidance Clinic, 1973), rather than first hand observations and research. Because children's coping skills are different at each stage of cognitive development, there is a need for research at each age level. Reactions of older children to natural disasters have been documented in such studies as those based on the Buffalo Creek disaster (Newman, 1976), and a lightning strike during a children's soccer game in Illinois (Dollinger, O'Donnell, \& Staley, 1984). There is also enlightening documentation of the reactions of children as young as six years old to the Three Mile Island Nuclear accident (Handforth et al., 1986).

\section{Purpose of the Study}

This study had three specific purposes. The first was to offer a developmental approach to understanding the cognitive and affective reactions of preschool-aged children to the Loma Prieta earthquake. The study evaluated and explored, through descriptive and predictive research, whether the socialemotional coping strategies of preschool children were delimited by their 
cognitive developmental level. The second purpose of this study was to research young children's beliefs about earthquakes, and their specific knowledge of the causes and effects of earthquakes. A third purpose of this study was to examine some variables that might affect children's ability to cope at that time. These included the place where children were at the time of the earthquake, and the reaction of the caretaker at the time of the earthquake. One possible outcome of this research could be to provide some insight into the appropriateness of current advice to parents and educators on dealing with preschool children's anxieties following a natural disaster. Hypotheses and Besearch Questions

In order to investigate the reactions of preschool children to a natural disaster, four hypotheses and associated research questions were formulated.

Hypothesis 1. That preschool children will experience disturbed sleep and eating patterns and separation anxieties following a moderately stressful natural disaster such as the Loma Prieta earthquake. To test this hypothesis the following research questions were posed:

Question 1.1. What proportion of children experienced sleep disturbances following the earthquake, and for how long?

Question 1.2. What proportion of children experienced disturbed eating habits following the earthquake, and for how long?

Question 1.3. What proportion of children suffered separation anxieties following the earthquake, and for how long?

Hypothesis 11 . That preschool children will be cognitively limited in their understanding of the causes and effects of natural disasters such as 
earthquakes. To test this hypothesis the following research questions were posed:

Question 2.1. What were children's concepts about the causes of the earthquake?

Question 2.2. What were children's concepts about the effects of an earthquake?

Question 2.3. What were children's perceptions about the location of the Loma Prieta earthquake in relationship both to their own home, and to the world in general?

Question 2.4. What was the children's cognitive awareness about a future earthquake?

Hypothesis Ill. That the older, and therefore generally more cognitively aware children were at the time of the earthquake, the less upset they would be by it. To test this hypothesis the following research questions were posed:

Question 3.1. How did the children's ages relate to the degree of their separation anxiety, sleep, and eating disturbances following the earthquake?

Question 3.2 How did the children's ages relate to the overall intensity of their affective reaction to the earthquake?

Hypethesis IV. That there would be an optimum situation for children to be in at the time of the earthquake that would produce the least cognitive dissonance and affective distress. To test this hypothesis the following research questions were posed:

Question 4.1. At the time of the earthquake, where was each of the children participating in this study? 
Question 4.2. How much damage did each of the children's homes sustain at the time of the earthquake?

Question 4.3. Were the children involved in this study with their parents at the time of the earthquake?

Question 4.4. To what degree did the children's caretakers remain calm at the time of the earthquake?

Question 4.5. Did the amount of TV that children watched correlate with their affective distress?

Significance of the Problem

Statistics reveal that each year about a dozen natural disasters of major proportions, and as many as forty of smaller magnitude, occur. ... The first concern of everyone in a disaster is with physical safety. This is as it should be. However, studies show that after a disaster, parents tend to deny or overlook the harmful psychological effects on their children. (Schaefer, 1984, p. 62)

This information led to the belief that there was a need to research ways in which parents, and other significant adults in preschoolers' lives, such as their teachers, could foster age appropriate coping skills for preschoolers, following a natural disaster.

Limitations and Delimitations of the Study

The following limitations and delimitations were placed on this study:

1. This study was limited to the children who were enrolled in the threeyear-old and four-year-old classes of the parent participation preschools in a single school district.

2. This study was delimited by the time and place of the Loma Prieta earthquake. 


\section{Definitions}

Cognition in this study was used to denote the functions of thinking, understanding, interpreting, relating, inferring, and symbolizing (Cowan, 1978).

Cognitive development is a common term that is used by post-Piagetian theorists. It denotes a broader scope than the term "intellectual development", having been expanded to include aspects of behavior other than knowledge. It suggests that children move sequentially, from lower level skills to higher level skills, in the development of knowledge, emotions, and social cognition concepts and competencies (Fischer, 1980).

eeping was assigned a definition formulated by N. Garmezy (quoted in Honig, 1986b, p. 51) who described it as "a pattern of behavioral response to novel situations, obstacles, and conflicts in which occur search, effort, direct action, and shaping of events."

Intensity of reaction was a term used in this research to describe the level of emotional energy exhibited by individuals in response to an environmental stressor.

Preschool children, for the purpose of this study, referred to children who had attained their third birthday by October 17,1989 , and who would be entering kindergarten in the fall of 1990 or the fall of 1991.

Separation anxiety was defined, for the purpose of this study, as a general syndrome of distress resulting from the parent's absence, or the thought of the parent departing. It could manifest itself in separation protests such as crying, or clinging to the parent (Damon, 1983). 
Social-cognition referred to the interaction of cognition and affect (feeling). It could be described as the way that people interpret sensations in terms of a cognitive category (Reimer, Paolitto, \& Hersh, 1979).

Stress in this study referred to "the pattern of specific and non-specific responses an organism makes to stimulus events that disturb its equilibrium and tax or exceed its ability to cope" (Zimbardo, 1988). 


\section{CHAPTER TWO}

\section{Review of the Literature}

This chapter describes literature dealing with the cognitive, social, and emotional development of preschoolers that has relevance to their reactions to the Loma Prieta earthquake. The literature search and review was divided into six sections: Piaget's theory of intellectual development, cognitive development perspective, preoperational thought, social cognition, stress and coping at the preoperational level, and children and disasters.

An information search was initiated through the card catalog at the Clark Library, San Jose State University. Literature on Piaget's theory of intellectual development and cognitive development was located for research into understanding how young children construct their knowledge. The card catalog and the Educational Resources Information Centers (ERIC) System were used for the purpose of locating more specific literature on the age-related stage of preoperational thought which could be used as a framework for analysis of results. The search in the area of social cognition proved that it was more difficult to find materials that related to preschoolers and the affective self. Social cognition, as a concept, was not a workable descriptor. Some materials were located through the initial search in the area of cognitive development. Other books reviewed in this area were recommended by two San Jose State University professors. For the fifth and sixth sections of this review, an information search was initiated through ERIC to seek existing studies on stress and coping in young children, and children and disasters. The following descriptors were used: Earthquake-children, natural disasters, children and disasters, and stress-coping. It was found that research into children and 
natural or man-made disasters had been undertaken using subjects who were older than the proposed population of this study. For the latter sections of this chapter, which dealt with applied theory, there was a large body of material in journal articles.

Piaget's Theory of Intellectual Development

A new approach to the theory of intellectual development was born in the 1920 's out of Jean Piaget's research into the structures and functions of intelligence. Up to that time the Behaviorist viewpoint, which dealt with content, in terms of how much information children could learn by rote, rather than with the structure of intelligence as a function of age, had been prevalent. Six Psycholegical Studies (1967) encompasses the heart of Piaget's philosophy as to how children construct their knowledge. Books that present detailed summaries, clarification, and confirmation of Piaget's framework include Herbert Ginsburg and Sylvia Opper's Piaget's Theory of Intellectual Development (1988), and Barry Wadsworth's Piaget's Theory of Cegnitive and Affective Development (1979).

Piaget suggested that children's thinking was a qualitatively different process to that of adults and that, "in estimating the child's conception of the world the first question, obviously, is to decide whether external reality is as external and objective for the child as it is for us" (Piaget, 1951, p. 3). He postulated that, as the individual evolved through the human growth process, so the variable affective and intellectual psychological structures evolved, in an invariant age related sequence. Ginsburg and Opper, in Piaget's Theery of Intellectual Development (1988), wrote: "Intellectual development proceeds through a series of stages with each stage characterized by a different kind of 
psychological structure and a different type of interaction between the individual and the environment" (Ginsburg \& Opper, 1988, p. 23). Thus each new experience to which children are exposed provides opportunities for cognitive growth.

This cognitive growth is achieved through the processes of assimilation and accommodation. Assimilation is the integration of external elements and it involves structuring or restructing every cognitive encounter into the existing cognitive organization. Schemata are the cognitive structures of the mind which each individual uses to adapt and organize the environment. When confronted with a stimulus, the child tries to fit it into existing schemata. When the concept to which the individual is exposed is integrated into existing schemata, there can be refinement, and schemata gradually become more differentiated as they mature. When the new stimulus does not fit into existing schemata, then accommodation takes place. The individual can either adapt an existing concept, or create a new schema into which to place the stimuli. Thus accommodation is a structural change that involves the development of new cognitive structures. Piaget described it thus:

All needs tend first of all to incorporate things and people into the subject's own activity, i.e., to "assimilate" the external world into the structures that have already been constructed, and secondly to readjust these structures as a function of subtle transformations, i.e., to accommodate them to external objects. (Piaget, 1967, p. 8)

However, the child's schemata will not be acccurate copies of reality because they reflect the child's current level of understanding and knowledge of the world. As Piaget wrote in Six Psycholegical Studies: "Mental development 
is a continuous construction comparable to the erection of a vast building that becomes more solid with each addition" (Piaget, 1967, p. 4).

Writing about Piaget's theory of intellectual development, Barry Wadsworth (1979) also emphasized the immaturity of young children's understanding of the world around them. He noted that:

The schemata have been constructed by the child. Since they are constructions, schemata are not accurate copies of reality. Their form is determined by assimilation and accommodation of experience, and over time they more closely approach reality in appearance. While the child is an infant, schemata are global--and, when compared to adults' schemata, extremely imprecise and frequently inaccurate. The processes of assimilation and accommodation that convert infants' rather primitive schemata into the more sophisticated adultike schemata obviously take years. (Wadsworth, 1979, p.16)

When these complementary functions of assimilation and accommodation that lead to cognitive growth and development are in balance, equilibrium occurs. According to Piaget: "All behaviors tend towards assuring an equilibrium between internal and external factors or, speaking more generally, between assimilation and accommodation" (Piaget, 1967, p. 103). Writing in Six Psychological Studies, Piaget compared physical growth and mental growth, suggesting that, just as the human body grows to maturity, "so mental life can be conceived as evolving toward a final form of equilibrium represented by the adult mind" (Piaget, 1967, p. 3). When there is an imbalance between the experiencing of a new stimulus and the existing cognitive structure then disequilibrium will occur. The process by which the individual moves from disequilibrium to equilibrium is called equilibration.

In a sense, development is a progressive equilibration from a lesser to a higher state of equilibrium. From the point of view of intelligence, it is 
easy to contrast the relative instability and incoherence of childhood ideas with the systemization of adult reason. (Piaget, 1967, p. 3)

Disequilibrium leads to the search for new knowledge, because it occurs when there is a discrepancy between children's experience and their prior knowledge. Piaget considered disequilibrium as the prime motivator in intellectual development. When faced with disequilibrium, there may be "disturbance, perturbation, or conflict" (Ginsburg \& Opper, 1988, p. 227) as children react in an attempt to regulate the problem. These regulations are dependent on the schema available. Ginsburg and Opper listed the three types of reactions to disturbances that had been identified by Piaget, namely alpha, beta, and gamma. Alpha reactions are shown by the very young preoperational child who either does not see an event as disturbing, or ignores it. The beta reaction, found during the later preoperational stage, finds the child modifying and reorganizing existing structures and seeking to make sense of a conflicting event. "Beta reactions are an attempt to adapt the system to disturbances perceived in the environment" (Ginsburg \& Opper, 1988, p. 228). Gamma operations come at a higher level of cognitive development and consist of constructing a system that allows ior anticipation of possible variations by means of inference.

In emphasizing the role that experience and motivation play in the development of intelligence, Piaget wrote that each intellectual stage sees increased mental capabilities that set parameters for what can be learned at that stage. Piaget suggested, however, that during the preconceptual and intuitive stages of child development (ages two to seven years) thought is 
always in a state of disequilibrium, or, at best, unstable equilibrium (Piaget, 1950).

Over the years, Piaget's research led him to a point where he was able to describe four age-related stages of intellectual development. Each stage had its own characteristics, and was an elaboration of the previous stage. The first stage, the sensorimotor period, comprised the period before language, lasting from birth to approximately two years of age. Then, as Piaget found: "With the appearance of language, behavior is profoundly modified both affectively and intellectually" (Piaget, 1967, p. 17) and consequently there is a new level of cognitive development. This stage has become generally known as the preoperational stage and lasts from two to seven years of age. Piaget saw it as: "a stage of intuitive intelligence, of spontaneous interpersonal feelings, and of social relationships in which the child is subordinate to the adult" (Piaget, 1967, p. 5). The stage of concrete operations followed, encompassing the years of "middle childhood." He viewed it as characterized by the beginnings of logic, by early morality, and by cooperation (Piaget, 1967). The final stage of development, coinciding with adolescence, was that of formal operations. This stage was based on the appearance of abstract thought and "the free activity of spontaneous reflection" (Piaget, 1967, p. 64). Pulaski (1971), in writing of Piaget's research on different levels of intellectual development, summed up his stages of cognitive development thus: "The young child can deal with concrete objects; the schoolchild can deal with them in thought; the adolescent is freed from the bonds of physical reality to soar into the realm of hypothetical possibilities" (Pulaski, 1971, p. 75). 


\section{Cognitive Development Perspective}

Since the 1950's many researchers have been confirming Piaget's theories. Other theorists who work in the area of cognitive development have been searching for different links between cognition and the structuring of concepts in order to explain cognitive growth. These theorists acknowledge the vast contribution of knowledge about intellectual development that has resulted from Piaget's research. Writing about research into cognitive development, Flavell suggested that:

Piaget's assimilation-accommodation model provides a valuable general conception of how people's cognitive systems might interact with their external environments. ... It is also a particularly useful vehicle for thinking about cognitive development - that is, about how the child's cognitive system might gradually evolve with maturation and experience. (Flavell, 1985, p. 6)

Books that present detailed summaries and critiques of Piaget's framework, while also posing questions about some aspects of Piaget's model, and proposing modifications to some aspects of his theory, include John Flavell's Cognitive Development (1985), and Intelligence and Experience by J. McV. Hunt (1961). Neo-Piagetians Jack Block (1982), and Robbie Case, who wrote Intellectual Development (1985), while sharing Piaget's fundamental philosophy of genetic epistemology, emphasized the individual difference factor. They also de-emphasized the specific age-related limitations proposed by Piaget, considering them too arbitrary (Case, 1985). Aspects of cognitive development that are especially relevant to this study, and to understanding how preschool-aged children deal with a new and disturbing event in their lives, include assimilation, accommodation, and equilibrium. These processes are described in the section on Piaget's theory of intellectual development. 
Jack Block, while agreeing with Piaget's position that assimilation and accommodation are processes necessary to cognitive growth, placed a different emphasis on these two functions. He viewed them as sequential rather than simultaneous processes and wrote:

The individual tries to assimilate objects or events to the established parameters of a scheme by arriving, easily or with difficulty, at a set of tenable parameter values that can generate an adaptive perception or action. Only when adaptation is not feasible by changing parameter values does the individual shift over to changing the parameters themselves, that is, to accommodation of the scheme. The adaptively oriented changing of parameter values (assimilation) and the adaptively oriented changing of parameters (accommodation) cannot be coincident, they must occur sequentially. (Block, 1982, p. 283)

Equilibration is also an area where Jack Block posed an alternative theory on cognitive development. Piaget had suggested that, from ages two to seven years, thought is always in a state of disequilibrium, or, at best, unstable equilibrium (Piaget, 1950). Block suggested that, rather than a balance between assimilation and accommodation, equilibration can be achieved solely through assimilation, and that "the assimilative mode has built-in priority over the accommodative mode" (Block, 1982, p. 286).

Another theory about equilibration, or the lack of it, was noted by Flavell. He stated that, according to Piaget, "states of cognitive conflict and disequilibrium impel the child to make cognitive progress" (Flavell, 1985, p. 289). Flavell's theory, however, suggested that when the child is presented with discrepant "nonassimilable" data the child can only make cognitive progress if four prerequisites are present in relation to that problem. He wrote that the child would seem to need the ability to do four things in sequence, namely: 
(1) attend to or notice both of the apparently conflicting elements in the situation; (2) interpret and appreciate them as conflicting and, therefore, problematic--something one cannot assume a child would automatically do; (3) respond to the sensed conflict by progressing rather than regressing--for example, by trying to explain it rather than by clinging defensively to his initial belief or refusing to have anything more to do with the problem; (4) come up with a better conceptualization of the situation that can resolve the apparent conflict and therefore "reequilibrate" his mental structure at a higher developmental level. (Flavell, 1985, p. 289)

Information-processing capacity is an aspect of the assimilationaccommodation process researched by Hunt. Like Flavell, he did not view the child as being automatically impelled towards equilibration. He wrote that:

If the child has the wherewithal to appreciate the contradiction and can cope with it, accommodative modification in the conceptual structures (revised expectations, attitude changes, etc.) occurs. If the child can appreciate the contradiction but cannot cope with it, the consequence is emotional disturbance. If the child cannot appreciate the contradiction, his interaction with that situation has no more effect upon his conceptual structures than does the proverbial "lecturing a pig about Sunday." In this sense, if corrective modification is to occur, it is essential that the problem should be appropriately matched to the schemata available in the child to permit the accommodation. (Hunt, 1961, p. 201)

Hunt discussed, in Intelligence and Experience (1961), the fact that sometimes there are stimuli that appear so contradictory to the child that there is cognitive dissonance. He wrote: "Discrepancies which are too large constitute a source of distress and negative motivation" (Hunt, 1961, p. 269). The notion of cognitive dissonance was first researched by Festinger who wrote A Theory of Cognitive Dissonance in 1957. He noted that, when contradictory stimuli are present, "Changing the environment itself in order to reduce dissonance is more feasible when the social environment is in question than when the physical environment is involved" (Festinger, 1957, p. 20). 
Flavell's research led him to believe that cognitive development is a sequential process, rather than the stage-like process proposed by Piaget. Writing in Cognitive Development, he discussed two possible types of cognitive development patterns, namely stages and sequences. He suggested that cognitive growth occurs in five types of sequences. These are addition, substitution, modification, inclusion and mediation (Flavell, 1985). In elaborating on his theory he noted that addition gives the child a second approach to a problem, while substitution can replace a less mature cognitive approach. Modification develops a cognitive entity to a more mature level and inclusion coordinates or integrates existing schemes into larger wholes. Mediation sequences are concerned with one cognitive entity assisting the development of another independent entity. Hunt concurred with Flavell's position on stage development, writing: "The stages are gross divisions and many questions remain unanswered" (Hunt, 1961, p. 287).

Case and Khanna, building on Piaget's work in dividing the sensorimotor stage of child development into substages, have proposed that:

Development may be divided into a series of several major stages, each of which is composed of four substages. . . . At each substage of development we have suggested, the child is able to coordinate a greater number of elements, with the final substage of one major stage being equivalent to the first substage of the next. (Case \& Khanna, 1981, p. 22)

Their proposal was that the period from one and one-half to four and onehalf years should be considered a major stage with four substages. They considered this the stage of development to which Piaget had devoted the least amount of research. The data for this period, they noted: "were gathered early 
in his career, before he had perfected the use of carefully graded sequences of logical tasks. The possibility that sequences of logically related structures might exist was not therefore fully explored" (Case \& Khanna, 1981).

John Flavell, and the other theorists whose views are presented in this section, believed that preschool-aged children "are generally more competent than we used to think" (Flavell, 1985, p. 48). In fact Flavell used the term "early childhood" in preference to Piaget's term "preoperational" to describe young children in the post-infancy stage. He considered Piaget's term "preoperational" a negative label because of the practice of analyzing children's errors, rather than recording their accomplishments, to describe this stage. The term "preoperational" is used in this study, however, to describe preschool-aged children, because the term, "early childhood" was considered to have too broad an interpretation.

\section{Preoperational Thought}

Literature about young children's perception of reality, and about how they learn through concrete experiences, was researched to gain understanding into the cognitive processes by which preschoolers might interpret the Loma Prieta earthquake. Because children at the preoperational level do not think as adults do, since their thought is a qualitatively different process, they have a different perception of reality (Piaget, 1951). In fact, reality may be indistinguishable from fantasy to the young child. Furthermore, since their learning is an interactive process, the quality and content of the physical and social environment they encounter can facilitate or impede their learning process (Flavell, 1985). 
Preoperational thinking is divided into two stages, the preconceptual period from 2-4 years of age, so named by Piaget because he considered the thinking of 2-4 year olds so primitive, and the intuitive period from 4-7 years of age (Piaget, 1967, p. 29). Intuitive thought is an extension of preconceptual thought that occurs as children become less egocentric, and more proficient at using symbols in their reasoning. Piaget suggested that children of four, five, and six years are capable of a type of logical reasoning. "Although logical structures are not fully developed at the preoperational stage, we do find what can be called semi-logic" (Piaget, 1970, p. 50).

Whereas Piaget's research identified areas that limit thought in the preoperational period, including egocentrism, centration, transductive reasoning, animism, the mixture of fantasy with reality, and a lack of understanding of causality, more recent research, including that of Gelman (1979) and Flavell (1985), has suggested that, for the preoperational child, "a more positive characterization is called for, one that stresses the developmental achievements of this period" (Flavell, 1985, p. 48). There is increasing evidence that young children have a limited concept of causality. Flavell (1985) suggested that, because children are "less able to talk and reason" about concepts than adults, it may not mean that the young child does not have "a variety of knowledge structures available to help her predict and understand the world in which she lives" (Flavell, 1985, p. 53). And Gelman, in opposing Piaget's view of the preoperational child as a young scientist constructing knowledge, believed that the young child shows a predisposition to understand physical and social causality (Bullock \& Gelman, 1979). Young children, however, appear to do relatively little cognitive monitoring of their own memory 
and cannot use reflection, in the sense that an adult would, to make sense of their environment (Flavell, 1985).

Setting limitations aside, the most significant advance of this stage of childhood is the development of language, and the accompanying symbolic function. In fact the appearance of symbolic function marks the beginning of the preconceptual period. "This function is the ability to represent something by a sign or a symbol or another object. It includes deferred imitation, that is, imitation that takes place when the model is no longer present" (Piaget, 1970, p. 45). Because preconceptual children have developed the ability to make one thing represent another, pictures are recognized as representing real objects, a concrete object such as a box or a block can become a symbolic representation. Then, as language develops, words come to represent objects, people, and events, enabling children to anticipate future actions. Piaget wrote:

In addition to all the real or material actions the child learns to master during this period, as he did during the preceding period, he now becomes able, thanks to language, to reconstitute his past actions in the form of recapitulation and to anticipate his future actions through verbal representation. (Piaget, 1967, p. 17)

As children realize that things continue to exist, even though they cannot be seen or heard, they can talk about things that are not present. They begin to engage in symbolic or "pretend" play which enables the 2-4 year old to construct a make-believe world. Piaget (1962) suggested that children cannot always distinguish between fantasy and reality, in fact they can believe anything that they choose (Piaget, 1962). Sometimes children mix fantasy and reality because they cannot explain what is on their minds, rather than because they are fantasizing (Gelman, 1979). Magical thought leads children who are asked 
a question to which they do not know the answer to construct a fanciful response, and a feeling of magical power leads them to believe that they have power over the elements of nature. Piaget described this behavior in The Child's Conception of the World: "There is magic by participation between thought and things, when the child is under the impression that reality can be modified by a thought, a word, or a look, etc" (Piaget, 1951, p. 134). There is "magic by participation of purpose. In this case objects are regarded as living and purposive" (Piaget, 1951, p.134). This area of magical thought also includes "magic by commandment, e.g. ordering the clouds or sun to go away" (Piaget, 1951, p. 134), and animism, the attribution of life to inanimate objects. Animism leads children to believe that physical forces have the same intents and affects that they do (Phillips, 1984). It is closely related to artificialism. Children do not think that anything occurs by chance, and Piaget (Piaget, 1962) theorized that the processes of thought related to artificialism entailed continuous assimilation to a preconceptual structure based on myth, with a lesser degree of accommodation. "This artificialist thought is therefore still far from being operational, since it is assimilatory in the egocentric sense of the term, and since it is imaged, its accommodation being inadequate to attain the generality of the conceptual schema" (Piaget, 1962, p. 250).

In the Child's Conception of Physical Causality (1966), Piaget discussed the connection between the limitations of artificialism and animism, the child's conception of material force, and what he termed "a system of physics peculiar to the child" (Piaget, 1966, p. 1). He suggested that, during the early stages of cognitive development, children's explanations of causality fall into four categories (Piaget, 1966). The first of these is psychological, centered on 
an idea both causal and final, and involving the notion of a motivating force, for example, God. Finalistic explanations of causality would offer neither origin nor consequence of a concept or event. Piaget used, as an example, the young child observing that "ducks have webbed feet so as to swim better." $\mathrm{He}$ considered that the child was implying "some idea of a divine plan" (Piaget, 1966, p. 259). The third type of causal relation described was phenomenistic causality, which, simply stated implies that: "Anything may produce anything" (Piaget, 1966, p. 259) so that random relationships are viewed as causal and:

The mind of the very young child, saturated as it is with dynamism, with finalism, with animism, with magic, with pre-causality, with artificialism, etc., when it is confronted with new phenomena establishes at random spatial and temporal contiguities, and sees relations between any one thing and another. (Piaget, 1966, p. 260)

Magical causality is the fourth type of explanation attributed to the young child. It disappears after age 5-6. It suggests an affinity between two things that enables them to act on one ariother and, according to Piaget:

The subject regards his gestures, his thoughts, or the objects he handles, as charged with efficacy, thanks to the very participations which he establishes between those gestures, etc., and the things around him. Thus a certain word acts upon a certain thing; a certain gesture will protect one from certain danger. (Piaget, 1966, p. 261)

Piaget also noted the "remarkable absence" in children's thinking as to how phenomena occur (Gruber \& Voneche, 1977, p. 144). When a causal connection is discovered, then an immediate inference is made about objects or events, and classes or relationships that may not exist are assumed (Piaget, 1974). Transductive reasoning is a feature of this preoperational function which can lead children to believe that, if $A$ is like $B$ in one respect, then $A$ is like $B$ 
in all respects. Summarizing preschoolers' concepts of causality, Phillips wrote: "For the preschooler, explanations are found in connections which constantly contradict one another and as things appear to be rather than in logical necessity and general laws of cause and effect" (Phillips, 1984, p. 16).

The way that children conceptualize space, time and causality are central to the child's understanding of death. Since the preoperational child does not have a stable concept of future time, death does not appear frightening. "From the age of three to five children do not understand the meaning of death as discontinuous with, nor in opposition to life" (Elkind, 1979, p. 282). Preoperational children live in the present, and death in the adult meaning of the concept is beyond their comprehension. "At best, preschool children understood death as a kind of change of state, being hungry or asleep, but as nonetheless continuous with life" (Elkind, 1979, p. 283). Phillips concurred with Elkind's position, writing: "Children younger than 6 rarely think that death is universal, inevitable or final. Animism and artificialism prevail" (Phillips, 1984, p. 18).

Basing her research on concrete experiences, rather than the interview technique, Rochel Gelman explored preschoolers knowledge of cause and effect. She did not rely on interviews because: "Children are not too verbal at that age, and they are notoriously bad at justifying their answers" (quoted in Pines, 1983, p. 49 ). Her conclusion was that $75 \%$ of the time, "even young children operate on an implicit theory of physical causality" (Pines, 1983). She also investigated in what ways young children distinguish between animate and inanimate objects, information that reflects on an understanding of causality. Thoughts or emotions were never attributed to rocks. However Gelman found 
that children did sometimes attribute feelings to dolls. In examining young children's knowledge she found that:

The children often talked about the inability of dolls to move on their own, apparently viewing this as a very important characteristic. In evolution, this distinction would help to focus attention on potentially dangerous animals. But it may also have been the source of confusion in some of the children whom Piaget questioned. To a small child, Gelman points out, the sun, wind, and clouds may appear to move from within. As in all intellectual development, much depends on one's knowledge base. (Pines, 1983, p. 50)

Egocentricity, another characteristic which is observed during the preoperational stage of development, can limit children, in both their manner of reasoning and their logic, to be concerned only with self and to see everything from their own point of view. In writing of the child's egocentricity Piaget stated:

In his manner of reasoning, equally, the child is only concerned with himself, and ignores more or less completely the points of view of others. But, in logic also, if the child sees everything from his own point of view, it is because he believes all the world to think like himself. He has not yet discovered the multiplicity of perspectives and remains blind to all but his own as if that were the only one possible. Also he states his views without proof since he feels no need to convince. The results of this are seen also in make belief, the tendency to believe without proof, the absence of deductive reasoning; in syncretism also which connects all things in terms of primitive subjective associations; in the absence of all relativity amongst ideas, and finally in "transductive" reasoning which, through the agency of syncretism, leads from one particular to another, heedless both of logical necessity and of general laws. (Piaget, 1951, p. 167)

Piaget suggested that preoperational children have difficulty understanding another person's emotional and intellectual point of view, because not only do they assume that all the world knows what is on their minds, but they are unaware that anyone holds a point of view that differs from theirs. Flavell (1985) 
took issue with these limitations of egocentricity postulated by Piaget and his suggestion that preoperational children cannot reconstruct their own reasoning, nor justify their arguments, because they do not think objectively. His research showed that there may be allocentric thought as well as egocentric thought at the preoperational stage, so that in some areas children may use an external frame of reference that is allocentric, rather than the internal egocentric framework. In writing about preschool-aged children, Flavell noted that: "Like older people, they are capable of representing the location of objects by means of an allocentric (external, object-referenced) spatial frame of reference, as well as by means of an egocentric (self-referenced) one" (Flavell, 1985, p. 71).

One of the reasons that Piaget calls children's thinking from 4-7 years of age "intuitive" is that their understanding of an object or event is centered on the one single most salient feature. This phenomenom is called centration and it is the tendency to focus on a single aspect of a problem while ignoring other aspects that are relevant. It leads children to focus on only a limited amount of the information available, usually the most salient feature. "He focuses on one dimension of a situation, fails to make use of another, equally relevant dimension, and therefore cannot appreciate the relations between the two" (Ginsburg \& Opper, 1988, p. 154). Centration can be compared with children's lack of connection between cause and effect. It is an inability to make the sequential associations that are part of a higher thought process.

To summarize, preoperational thought differs from adult thinking in its egocentrism, its lack of concreteness, and its lack of distinction between fantasy and reality. It is limited by irreversibility (whereby children cannot mentally undo or reverse actions), centration (characterized by children focusing on only one 
aspect of a problem although two or more aspects are relevant), transductive reasoning (in which events that occur together are assumed to be casually related), and animism (the belief that elements of the world of nature are alive). Social cognition

The relationship between cognition and affect is known as social cognition. A smaller body of literature was found in this area. Piaget's Six Psychological Studies (1967) and Cowan's Piaget: With Feeling (1978) proved rich sources of material about the relationship between intellect, emotion, and feelings. There is a chapter on social cognition in John Flavell's Cognitive Development (1977) and Barry Wadsworth's Piaget's Theory of Cognitive and Affective Develorment (1979) examines Piaget's studies on affective development. Stress, Appraisal and Coping by Lazarus and Folkman (1984) discusses the relationship between cognition and emotion. Contrary to the view held by many of those reading Piaget's work, who think that his theories were concerned only with intellectual development, Piaget believed that cognitive and affective development could not be separated (Piaget, 1967, pp. 33-38), and that there is no cognition without affect and no affect without cognition. Cowan noted, however, that "unfortunately we do not yet have a body of empirical data concerning the interrelations among cognitive, social, and emotional development in the young child" (Cowan, 1978, p. 136). It was theorized that "thought and feeling are intimately related in the development of the young child" (Case, 1984, p. 423), so that each change in thought could lead to a change in feeling, and that, in researching properational children's reactions to a natural disaster, there would be connections between their thoughts about their experience, and their emotions concerning it. 
Traditionally throughout history, thought and feeling were separated (Lazarus \& Folkman, 1984), the implication being that thought represented reason and was not related to emotion or passion. Information on affect was long held to belong to the area of psychology, and the literature dealing with social and emotional development in childhood tended to be presented from that perspective. Many researchers who study intellectual development today still separate the affective and cognitive domain and do not touch on the area of social cognition. As Lazarus and Folkman wrote:

Although the place of emotion has been elevated in cognitive theories of emotion, in that it is seen as the product of highly complex cognitive activity, the impression remains that, as in older times, cognition and emotion, and motivation too, are separate and distinct entities that affect each other. (Lazarus \& Folkman, 1984, p. 273)

Piaget's findings (1967), however, emphasized the possibility that cognitive factors critically affected emotional development, and that, throughout childhood, the development of the affective self, namely emotional and social cognition, paralleled intellectual development. He wrote: "With respect to the affective life, it has frequently been noted how extensively emotional equilibrium increases with age. Social relations also obey the same law of gradual stabilization" (Piaget, 1967, p. 3).

- Current social cognition theories offer three differing viewpoints. The first of these suggests cognition as a necessary precursor to emotion, the second suggests emotion as preceding, and therefore effecting, cognition, and a third integrated approach hypothesizes that emotion is both an antecedent variable and an outcome variable of the cognitive-emotion relationship (Lazarus \& Folkman, 1984). Piaget's position was most consistent with the third theory, 
stating that there is never a purely intellectual action, and there is never a purely affective act (Piaget, 1967). He wrote: "Always and everywhere, in objectrelated behavior as well as in interpersonal behavior, both elements are involved because the one presupposes the other" (Piaget, 1967, p. 34).

The domain of social cognition has three general preconditions (Flavell, 1985). The first of these is existence, which refers to the fact that the young children need to know that a concept exists in order to think about it. "The point is a most unprofound one: There scarcely can be any thinking about socialcognitive phenomena if the very existence of such phenomena is not yet represented to the thinker" (Flavell, 1985, p. 121). Having acknowledged the existence of feelings, children have also to have the disposition, or need, to engage in an act of social cognition. Thirdly, children require the skill or capacity to perform social thinking. Social and non-social cognition share many similarities, both developing in sequentially once language is present. Barry Wadsworth noted that:

During the sensori-motor stage, past events and experiences cannot be reconstructed because they are not represented by the child. With the capacity for reconstruction of the cognitive and affective past, behavior can assume an element of consistency that was not possible before representation. With the reconstructed past an element in current behavior, affect is less tied to immediate experience and perception than it previously was. Behavior can become a bit more stable and predictable. (Wadsworth, 1979, p. 94)

Since, according to developmental theorists, every stage of development is built on a previous stage, the affect of infancy will still be present in the preoperational child, for example reflexive feelings of happiness or unhappiness, contentment or fright (Wadsworth, 1979). Infant social-cognitive 
development can be characterized as a process of differentiation between self and others (Flavell, 1985), until object permanence takes over. Then the child whose mother is absent can "bridge her physical absences by symbolicrepresentational means and thereby sustain an enduring affective link to her" (Flavell, 1985, p. 135). This stage is still present in preoperational children so that, although parents may view their children as competent and resourceful, a shaky self-concept can lead to a regression to early stages of affective development such as separation anxiety. Cowan wrote: "the preconceptual child's concept of self is a preconcept" (Cowan, 1978, p. 137), so, although these children who are past infancy can visualize a parent or caretaker who is not present, their emotional reactions can often go either way, depending on the interpretation applied to a situation (Reimer, Paolitto, \& Hersh, 1979). When children are not sure how to cognitively interpret a given event, then it may not be possible for them to experience the appropriate emotional reaction.

Cowan (1978) researched Piaget's theory that cognitive factors critically affect emotional development. In discussing the findings of Piaget, and Lazarus and Folkman, he wrote of cognitive structures limiting children's understanding of the world, influencing their perception of what is pleasurable and what is threatening. The feelings of young children center on a particular event, and then change when events change. Their cognitive apparatus transforms adult concepts and ideas to their developmental stage (Cowan, 1978), with emotion being the motivator for disequilibration and subsequent structural changes in social knowledge (Cowan, 1978). Children's egocentrism is seen in their social interactions, and in their lack of perception in dealing with problems. This is because only one variable or attribute can be processed at a time. Thus 
children's social thought is characterized by moving from one event to another without the ability to integrate the event (Piaget, 1967). Social cognition proceeds from the surface, or children's perception of appearance or behavior, moving to depth, or inner thoughts and feelings as children grow older (Flavell, 1985).

Stress and Coping in Preoperational Children.

Hans Selye (1956) defined stress physiologically as the nonspecific bodily response to a demand. Physiological stress reactions are automatic, and consequently outside the area of conscious control. The body has an alarm reaction that mobilizes the body's defenses for restoration of inner balance. But the psychological reactions to stress are learned behaviors dependent on emotional, social and cognitive development (Zimbardo, 1988). Stress can arise from internal factors or external factors, and it can be a chronic or acute factor in children's lives. Disasters could be termed acute stresses. They "arise suddenly, are isolated instances, and their impact may not last long" (Honig, 1986a, p. 51). Newman (1976) found that children's responses to disaster varied according to three circumstances, namely their intensity of exposure to the event, their developmental level, and their perception of family reactions.

There are several interrelated components of stress. The first is a stressor, or the event that causes disequilibrium and forces children into an adaptive response. Second is the evaluative process of cognitive appraisal about which Honig wrote: "Differences in the cognitive appraisal of stressors lead to marked individual differences in children's reactions to potential stressors" (Honig, 1986a, p. 52). Next are coping skills, including tears, thinking skills, and play with peers, and then coping resources which include the ability to ignore the 
unpleasant situation, or to "find and accept substitute satisfactions and comfort" (Honig, 1986a, p. 52). Stress makes an unusual demand for adaptation of the child, adaptation that may not be possible, given the cognitive developmental level of the child. The effect of a stressor was described by Zimbardo who wrote: "Once a stressor has been interpreted as threatening to one's well-being or self esteem, a variety of intellectual functions may be adversely affected. In general, the greater the stress, the greater the reduction in cognitive efficiency" (Zimbardo, 1988, p. 504).

Cognitive activity is an essential part of an emotional response because it gives meaning to an event and leads to the evaluation that will cause the emotional response. Lazarus and Folkman (1984), suggested that cognitive appraisal is an "integral feature of emotional stages" and that it "always mediates emotional reactions to a greater or lesser degree, although emotions once generated can then affect the appraisal process" (Lazarus \& Folkman, 1984, p. 278). They wrote that:

The person must sense threat and distinguish it from nonthreat or else be constantly in a state of psychological stress or crisis. We suggest that cognitive appraisal is the mediating process that sets the whole train of psychological events into motion, including coping activity, the emotional reaction, and the somatic changes that are part of any stress state. (Lazarus \& Folkman, 1984, p. 284)

They also noted that not all sources of stress are "amenable to mastery, or even fit within a problem-solving framework" (Lazarus \& Folkman, 1984, p. 138). Natural disasters are an example they cited of a source of stress that does not lend itself to mastery and is better addressed through fostering coping skills that: 
Are concerned with managing emotions and maintaining self-esteem and a positive outlook, especially in the face of irremediable situations. Coping processes that are used to tolerate such difficulties, or to minimize, accept, or ignore them, are just as important in the person's adaptational armamentarium as problem-solving strategies that aim to master the environment. (Lazarus \& Folkman, 1984, p. 139)

Philip Zimbardo, writing in Psychology and Life (1988), noted that stress response includes a variety of emotional reactions, ranging from exhilaration at exciting challenges, to irritation, anger, anxiety, and sleep problems. Thomas and Chess researched the reactivity to the environment, finding that the level, or intensity, of the emotional energy involved in the individual's reactivity may have a positive or negative quality, which, in turn, would affect mood quality (Chess, 1986). Mary Hanneman Lystad, when she wrote about family implications of children's responses to disaster stated that: "It is natural for children to be afraid of being alone or of sleeping alone in the dark for a period of time following a disaster" (Lystad, 1984, p. 46) and Rutter (1981) noted that stressful situations will elicit strong separation anxiety and consequently result in stronger attachment behavior. Zimbardo found that "most stress is acutely uncomfortable, producing only negative emotions and efforts to lessen the discomfort in direct or indirect ways" (Zimbardo, 1988, p. 503). These ways of lessening discomfort are known as coping skills. Writing in Young Children, Alice Honig quoted Garmezy (1981) in defining coping as "a pattern of behavioral responses to novel situations, obstacles, and conflicts in which occur search, effort, direct action, and shaping of events" (Honig, 1986b, p. 51). She used Rutter's term, protective factor (1979), to describe variables that decrease stressor effects. These variables included: close mother-child attachment, and 
a nurturant parent-child relationship. However, before adults can lessen the feelings of stress for their children, they must find ways of dealing with their own anxieties. Writing about children and stress, Abigail McNamee noted that:

For the most part their response is dependent upon the attitudes and actions of adults around them. ... Although the effects of disaster upon children cannot be totally eliminated, the deleterious effects can be lessened. First, adults must find ways of dealing adequately and promptly with their anxieties in order not to transmit them to the children. (McNamee, 1982, p. 72)

In writing about the characteristics of thought of preschool children, Phillips (1984) discussed appropriate ways in which adults can help children with fears. She suggested that children need to have their questions answered in terms that they can understand. She noted that:

To misinform children in order to relieve one's own anxiety (as in telling a child that a dead parent has "gone away", or an injection is going to be "just like a mosquito bite") is to set in train a string of anxieties that may be longlasting. (Phillips, 1984, p.19)

Honig suggested that, when adult support systems are missing in the lives of preschool-aged children, their lack of cognitive sophistication may intensify the effects of stressors. She made the point that, although young children cannot independently seek out an alternative supportive adult, "caring preschool teachers can be particularly significant in these children's lives" (Honig, 1986b, p. 52). As well as finding time for the individual child, in times of stress the teacher can talk with a group of young children about stressors. The teacher can ask children who are comfortable about an experience to share what it was like. "Such talks give courage to a child who may be hiding secret sorrows, thinking he or she is all alone with these troubles, or the only one scared by 
them" (Honig, 1986b, p. 57). The teacher can also encourage children to act out stressful events and subsequent coping skills.

Young Children and Disaster

It was considered that the implications of some studies of the effects of disasters on school-age children would throw light on this research. Those perused provided data on how children understood their experiences, what their emotional reactions to disaster were, and how they coped. They also provided data for formulating a parent questionnaire, and for measuring emotional reactions.

Allen Handford and his associates studied a randomly selected group of 35 children with an age range of 6 to 19 years, in 1980 , eighteen months after the Three Mile Island nuclear accident, in order to contribute a systematic study of children's reactions under the stress of disaster (Handford et al., 1986). Survey items explored perceptions of the accident, reactions to it, and changes in behavioral patterns. The psychological impact of the disaster on parents was also measured, through a question posed to their children. The majority of the children who felt their parents coped well, said the parents were calm and reassuring. Analysis of the emotional content of the children's responses, which was converted to individual intensity-of-reaction scores, revealed that $73 \%$ of the subjects were frightened during the incident, $42 \%$ termed the evacuation "fun" and $15 \%$ were angry about it. Interestingly, the researchers found that there was a marked discrepancy between what children said they felt about the disaster, and what parents perceived as being their children's feelings and experiences. 
These researchers reviewed the data from a developmental perspective. Their analysis revealed that, whilst older children's concerns following the disaster were more focused, the younger children in the study group expressed "vague and undifferentiated" responses, for example that TMI "might be dangerous." The researchers found that, although age was a factor influencing the coping process employed by the subjects, "no single coping mechanism was shown by a majority of children." One third of the subjects were reported as using partial denial as a coping mechanism. The youngest group of subjects, with a mean age of 8.2 years, were found to display an absence of memory of the disaster.

In September 1977, a truck crane struck a pedestrian overpass leading to an elementary school in Lansing, Michigan. Twenty children were on the overpass at the time, and approximately 100 children witnessed the accident. Gaston Blom, M.D., was called in as a consultant in dealing with the effects of the accident on school children and their parents. In a paper published in 1986 he reported that a broad school based assessment and intervention program was sufficiently successful to achieve the primary goal in "assisting a large population of children, their parents, and school personnel to assimilate a catastrophic event and to resume adaption again to a predictable world" (Blom, 1986, p. 337).

Systematic data regarding individual children and families was gathered following the initial crisis intervention. Data gathered included information on children's behavior over the time since the accident, current adjustment of children and parents, and parental opinions regarding ways of helping children resolve their feelings about the accident. Analysis of the data revealed that 
$11 \%$ of the children were still upset 4 to 6 weeks after the accident. Findings on child adjustment reactions and stress behaviors showed that 5 to 8 year olds had fewer stress symptoms than older children, but more frequently displayed phobias and somatic behavior. Data were available on differences between the reactions of boys and girls:

Boys were distinguishable from girls in taking a longer time to recover and in displaying a higher frequency of sleep disturbances, fighting and fears; girls showed more startle reaction to noise, asked many questions and thought frequently about the accident. (Blom, 1986, p. 342)

In summarizing his findings, Dr. Blom noted that, while the school accident was minor when compared to other disasters, it had a significant emotional impact on children.

Reporting in the Journal of Consulting and Clinical Psychology, Stephen Dollinger and his colleagues, discussed the results of their study of child victims of a lightning-strike in 1980. The purposes of the research included the study of the mental health effects of disasters. The researchers based their work on the fact that, while sociological and psychological post-impact studies have found little conclusive evidence for emotional problems, psychiatric studies have reported marked psychopathological reactions amongst disaster victims. The research was undertaken using a parent questionnaire. Mothers were asked to complete a 46-item questionnaire concerning their children's sleep adjustments, somatic complaints, and other problems. Children were also interviewed, and based on the amount of emotional upset that was apparent, they were given a rating. A 4-point scale was used with a score of 0 for no upset, 1 for mild or trasnsient upset, 2 for moderate upset, and 3 for severe 
upset. Examples of moderate upset included separation anxiety and generalized anxiety during the first week after the disaster. Examples of severe upset included bed-wetting. The researchers reported that many children favored "not thinking about it" or suppression as a mode of coping with the disaster. The study also found that parents' and children's reports on fears did not correlate and that "children's fear experiences often occur privately, at a time and place when parents do not witness them" (Dollinger, O'Donnell, \& Staley, 1984, p. 1037).

The mental health of child disaster victims was researched more recently by Lewis Aptekar and Judith Boore of San Jose State University (1990). In reviewing the literature on children and disasters they reported on the variability of children's reactions to disasters, in particular the effect of "communicated anxiety" between parent and child. They noted that separation anxiety could appear in the child, because, following a disaster, there was "a regression to an earlier level of dependency on parent figures" (Aptekar \& Boore, 1990, p. 10). They implied that, when the parents were overwhelmed, then they tended to minimize their children's reactions. In discussing coping skills of children, they reported that allowing children to help themselves following a disaster leads to a sense of self-efficacy which will mediate the stress.

\section{Summary}

This review of the literature has attempted to assess the intellectual development and underlying cognitive structures and affective behavior of preschool-aged children and to seek a relationship between preschool-aged children's understanding of, and reactions to a natural disaster such as the Loma Prieta earthquake. Careful study of the work of Piaget, and later theorists 
in the area of cognitive development, revealed that preoperational children are active participants in their own learning process. Accommodation and assimilation may be present in every experience. However, when an event, such as a natural disaster, does not fit into an existing cognitive scheme, there is not automatic adaption or equilibrium. Sometimes children are not able to form a sufficient new scheme to deal with the discongruent information. Furthermore, preoperational children are restricted in their understanding of the environment because they are rooted in an egocentric world, where perception dominates reasoning, and judgements, therefore, are based on perceptions of events, not conceptual reality.

As young children assimilate new experiences into cognitive schemes, affective schemes simultaneously undergo change. Indeed, for Piaget, the cognitive and affective selves cannot be separated. There is no thought without feeling. Descriptive accounts of children's response to stress showed parallels between understanding and response, and cognitive development. These studies also showed the extent to which the way that parents coped with a disaster reflected on the degree of trauma for their children, and that the effects of disaster could be lessened when children's social world remained intact.

The knowledge base accumulated in this review provided an informational framework for constructing a questionnaire to collect data about preoperational children's response to the Loma Prieta earthquake. The methodology is described in the following chapter. 


\section{CHAPTER THREE}

\section{Methodology}

Introduction

This study examined the cognitive and affective reactions of young children to a natural disaster through an investigation of the reaction of preschool-aged children to the Loma Prieta earthquake. The study was conducted through descriptive and predictive research, using a parent questionnaire to gather data. The research had three specific purposes. The first was to offer a developmental approach to understanding the cognitive and affective reactions of preschool children to the Loma Prieta earthquake and to explore whether the social-emotional coping strategies of preschool-aged children were delimited by their cognitive developmental level. The second purpose of this study was to research young children's beliefs about earthquakes, and their specific knowledge of the cause and effects of earthquakes. A third purpose of this study was to examine if the intensity of children's reactions to the earthquake was related to variables such as their whereabouts at the time of the earthquake, their caretaker at the time of the earthquake, and the amount of damage their home sustained in the earthquake. This chapter describes how the study was designed, and how data was gathered, summarized, and analyzed.

\section{Research Method}

\section{Introduction}

Since one of the intents of this study was to test hypotheses concerning patterns in the reactions of preschool-aged children following the Loma Prieta earthquake, this study was conducted through descriptive and predictive 
research. Descriptive research was best suited not only to reporting and describing conditions and situations, but also to interpreting behaviors. It was also an appropriate tool for analyzing anecdotal material. A questionnaire was used to gather information for the data base. The predictive research was intended to provide information to add to the limited body of knowledge available to date about preschooler's reactions to a natural disaster, and to offer expanded information for parents and teachers to acquire skills to help preschoolers cope, following an earthquake.

\section{Research Design}

A parent questionnaire was the tool for data collection because it provided a method of reaching a large population in a specific area. Time was a consideration. The questionnaire could be completed by a parent in about fifteen minutes. Parent interviews would have required a much greater time commitment on the part of the parent. Another consideration was that the families involved in the study were too numerous to be visited on an individual basis. The questionnaire was structured to provide data to answer the research questions. No psychological terms were used in the structuring of the questions, instead, terms that would be generally familiar to parents such as "sleep disturbance" were used.

\section{Population and Sampling}

The questionnaire developed for this study was distributed to the parents of the 250 children enrolled in the three-year-old and four-year-old classes of the half-day parent participation preschools in the Fremont Union High School District in the Fall of 1989 . Parents returned 114 completed questionnaires to their classroom teachers. Nine questionnaires were discarded because the 
children's ages were outside the specific range of from 36 months to prekindergarten. The population for this study consisted of 105 parents who returned a completed questionnaire, and 106 children.

This school district encompasses the cities of Cupertino and Sunnyvale, and the west side of the city of San Jose. These preschools were selected because they presented a stable population of families who lived in areas where, although the structural damage from the Loma Prieta earthquake was moderate to mild, the shaking and aftershocks were quite severe. It was surmised that, since these parents were involved in their children's education, and had enrolled in parenting classes, there was a strong possibility that they would take the time and effort needed to complete and return the questionnaire. The population comprised 50 boys, 51 girls and 5 children whose sex was not recorded on the questionnaires. The ages on the day of the earthquake ranged from 64 months to 36 months, the average age being 50.1 months. The majority of the children came from middle-class families. Overall in this program the children were from intact families. Approximately $17 \%$ of the children were from ethnic minority families.

The Directors at each of the four sites of these parent participation programs were contacted and asked to distribute the questionnaire. Parental permission to use data about their children was sought through a letter to the parents. A copy of the questionnaire is given in Appendix $A$.

4. Data Collection

4.1 Instrumentation and Tools

Since one of the purposes of this study was to record specific behaviors during a period of time following a natural disaster, it was essential to construct 
a questionnaire that would record ordinal data about the length of time that children were disturbed, and the degree to which they were disturbed. Part I of the questionnaire contained only forced choice questions, that could be responded to by checking the appropriate answer. The questions elicited information in areas such as children's behaviors in the month following the earthquake, their whereabouts at the time of the earthquake, and their ideas about where the earthquake occurred. Part II consisted of four open-ended questions, two for parents to answer themselves, and two for them to pose to their children. Parents were asked to respond as to what helped their child cope with the earthquake. They were asked to question their children as to why earthquakes happen, and what might happen should there be another earthquake. It was considered more appropriate, given the ages of the children involved in this study, to have the parent rather than an unknown interviewer elicit children's responses to the questions in Part II. Part III of the questionnaire used a 7 point scale ( 1 = no apparent distress, 7 = extremely upset), for parents to rate how upset their children were by the earthquake, and by the aftershocks. The questionnaire was field tested with five parents of preschool-aged children, who met informally with the researcher to complete a draft copy of the questionnaire, and seek clarification where a question or term was unclear. The researcher established that, where the occurrence of a specific behavior required a certain degree of judgment, the parents understood the rating scale. This preliminary testing established questionnaire reliability, and proved effective in obtaining the needed data. 


\subsection{Data Processing and Analysis}

All the information gathered from Parts I and III of the questionnaires was charted on a matrix using the Microsoft Excel 2.2 program. This program was also used to sort the data, for statistical analysis, and for the charts and tables. ANOVAs and simple regressions were calculated using the StatView program. Qualitative data was analyzed and interpreted through the use of descriptive narrative. Analysis of the data collected was treated through its relationship to the research questions.

The first two research questions (1.1 and 1.2) pertained to sleep and eating disturbances. Data from Questions 6 and 7 was charted on a matrix and analyzed to find out how many children experienced these disturbances, and for how long. The distribution between boys and girls, and an average age for the group were also calculated. Results of sleep disturbances were presented a table. Research question 1.3 was answered using data from Questions 8 through 11, all of which surveyed separation anxieties. Again, the information was put into matrix form, and analyzed to find the number of children who experienced separation anxieties, and the length of time the anxieties persisted. The average age of those experiencing separation anxieties was calculated, and the distribution of boys and girls.

Research questions 2.1,2.2, and 2.3 surveyed the area of cognitive awareness as it pertained to causality. Anecdotal material from Questions 1 and 2 in Part II was grouped according to common themes in the children's answers. It was presented through descriptive narrative, and summarized in tabular form. It was found that the majority of the responses fell into several broad categories. These categories were then subjected to further analysis to 
find the average age and age range in each category. The anecdotal material that was analyzed is presented in Appendices B and C.

The answers to Questions 14,15 , and 16 were studied to find out how cognitively aware children were of the location of the earthquake. Answers were grouped by age and put in tabular form. ANOVAs were run to check if there was a statistically significant relationship between age and concept of the earthquake's location. To find out how concerned children were about future earthquakes, the information from Questions 23 through 25 was analyzed. Some anecdotal material was also found in Part II, Question 2. Questions 17 and 18 gave information about children's reactions to aftershocks and unrelated shaking. Results are presented through descriptive narrative and tables.

To answer research question 3.1, the responses to Question 6 were sorted and subjected to a one-way ANOVA, to look for age differences in the extent and duration of sleep disturbances. Presence or absence of sleep disturbance served as the independent variable, and age as the dependent variable. Question 7 received the same treatment in order to examine the relationship between age and disturbed eating habits. The responses to Question 9 were subjected to simple regression analysis to examine the relationship between children's age and the extent of separation anxiety they experienced after the earthquake. For the analysis, age was used as the predictor variable, and the extent of separation anxiety as the predicted variable.

Research question 3.2 required that intensity of reaction scores be formulated from the data. A matrix was constructed using each subject's answers to 8 questionnaire items, namely, Questions 6 through 11 in Part I, and Questions 1 and 2 in Part III. Information from the questionnaires was assigned 
the numerical ratings described in Table 1. These ratings were then totaled for each of the participating children to obtain an overall intensity of reaction score. The highest score that could be obtained was 54 (See Table 1, p. 79). A simple regression was then run, with the children's age as predictor, to ascertain if there was a relationship between age and degree of upset. The data used for this scale is presented in Appendix D.

Research questions $4.1,4.2,4.3$, and 4.4 , which related to the place where children were at the time of the earthquake, and to the reactions of their caretakers at that time, were answered with information from Questions 1, 2, 4, and 22. The data was sorted and charted according to where the children were at the time of the earthquake, and how much damage their home sustained. It was then sorted according to who was with each of the children at the time of the earthquake, and lastly according to the degree of upset of the caretakers. ANOVAs and simple regressions were then calculated to look for statistically significant relationships between these variables and the intensity of children's reactions.

The other dimension considered in gathering data and reviewing variables that could affect children's reactions to the Loma Prieta earthquake, was exposure to information about the earthquake through TV viewing. To answer research question 4.5, data from Question 20 was analyzed. The information from this question, which asked parents how much TV coverage of the earthquake their children had watched, was presented in tabular form as a comparison with the children's intensity of reaction ratings, and a simple regression was calculated to seek statistical significance. Inferences could be drawn from the analysis of the results of research questions $4.1,4.2,4.3,4.4$, 
and 4.5 as to what circumstances helped or hindered children's coping after the earthquake.

A summary of the Questionnaire items used to answer each of the research questions is presented in Table 2 (See Table 2, p. 81). 


\section{CHAPTER FOUR}

\section{Besults and Discussion}

The cognitive and affective reactions of preschool-aged children to the Loma Prieta earthquake were examined in relationship to their level of cognitive development. The information gathered through the parent questionnaire, and the results of the analysis of the data, are presented in this chapter. Raw data are included in Appendices B, C, and D.

\section{Hypothesis 1}

The first hypothesis stated that preschool children would experience emotional difficulties manifested as disturbed sleep and eating patterns, and unease at separating from their parents, following a natural disaster such as the Loma Prieta earthquake. Analyzing the data from Question 6 (see Appendix A) revealed that 39 percent of the children $(N=41)$ suffered from disturbed sleep patterns after the Loma Prieta earthquake. Of these, 18 were boys, 18 were girls and 5 were children whose sex was not recorded in the questionnaire. The average age of these children was 50.8 months.

While twenty three of these children had sleep disturbances for a few days, and 6 for a few weeks, 11 percent of the subjects $(N=12)$ experienced sleep disturbances for more than a month. Three children were still experiencing disturbed sleep patterns when the questionnaire was completed, six months after the earthquake (See Table 3, p. 86). Of the children whose sleep patterns were disturbed for more than a month, 7 were girls, and 5 were boys. Their average age was 50 months. These findings corroborate those of Lystad (1984), who reported that children were afraid to sleep alone after a natural disaster. These results also closely match Blom's finding (1986) that 11 percent 
of the subjects involved in a traumatic incident were still experiencing sleep disturbances 4-6 weeks later. However they differ from Blom's findings in that he found that boys displayed more upset than girls.

The data from Question 7 (see Appendix A) showed, on analysis, that 10.5 percent of the subjects ( $N=11,6$ girls and 5 boys), were reported as having disturbed eating habits after the earthquake. Their average age was 40.9 months. In four cases, parents reported that their children experienced disturbances in their eating habits for a few weeks.

Reviewing the data from Questions 8 and 9 (see Appendix A), it was found that 45 percent of the subjects (47), appeared to suffer no separation anxieties after the earthquake, and furthermore were willing to be left alone in a room at home following the earthquake. However, 46 percent of the children $(\underline{N}=48,21$ boys and 27 girls) did suffer some difficulties in separating from their parents following the earthquake. Their average age was $\mathbf{5 2 . 1}$ months. Further analysis revealed that 33 children experienced separation anxiety for a few days, 7 for a week, 8 for a month, and for one child it was still occurring at the time that the questionnaire was completed.

Analysis of data gathered from answers to Question 8 (see Appendix A) revealed that 45 percent of the children $(\underline{N}=47)$ were unwilling to be left alone in a room in their own home on the day following the earthquake. This behavior persisted for up to a week for 26 children, from a week to a month for 12 children, and for more than a month for 6 children. These subjects comprised 26 girls, 19 boys, and 2 children whose sex was not recorded. Their average age was 51 months. The length of the subjects' sleep and eating disturbances and separation anxieties and fears were compared and it was found that, 
overall, sleep disturbances were exhibited for the longest time following the earthquake (See Table 4, p. 87).

Data from Questions 10 and 11 (see Appendix A) gave the following information: six children resisted going to school during the week following the earthquake, 3 boys and 3 girls. Six children resisted visiting friends' homes during that week, all giris. Three children fell into both these categories. Interestingly enough, they were all girls, with an average age of 50 months. Again, this information differs from Blom's findings that boys would be more upset than girls.

Results supported the hypothesis that preschool children would experience emotional difficulties following a natural disaster. As expected, a significant percentage of the subjects experienced both difficulty in sleeping, and separation anxieties. Analysis of the data agreed with Rutter's findings (1981) that not only do stressful situations elicit separation anxiety, but that characteristic attachment behaviors, such as seeking close proximity to the parent, tend to increase at times of stress. This is supported by anecdotal material which showed that, where disturbed sleeping patterns were reported, many of the children wanted to sleep with their parents. Results suggested that, for these preoperational children, thought, and therefore feelings, could be tied to perceptual evaluations that led to limited cognitive evaluation, a consequent lack of accommodation, and, in some cases, cognitive dissonance caused by an inability to cope with the discongruent information produced by the experience of the earthquake. The fact that children were afraid to sleep alone, or to go into rooms associated with the earthquake, could indicate mental confusion in the subjects, arising out of the fact that mental symbols became 
partly detached from the concrete experience of the earthquake and were extended into fanciful concepts.

The children who suffered no emotional distress may not have appreciated the contradictions of the earthquake stimuli, and, since their cognitive structures were not changed, they displayed no affective change. The reactions of more than half of the subjects experiencing emotional distress closely matched research showing that, when children experience acute stress as an isolated incident, there is only short-term imbalance between assimilation and accommodation, or vice-versa, and therefore emotional disturbance will be short-term.

\section{Hypothesis II}

The second hypothesis stated that preschool children would be cognitively limited in their understanding of the cause and effects of natural disasters such as earthquakes. Anecdotal material from answers to Question 1 in Part II of the questionnaire, which is presented in Appendix $B$, was reviewed in order to study the children's concepts about the cause of an earthquake (See Table 5, p. 88). When asked: "Why was there an earthquake?" or "What made it happen?" 23 children responded: "I don't know." This group of children comprised 13 girls and 10 boys, with an average age of 46.7 months.

Thirty-six children, average age $\mathbf{5 0 . 6}$ months, offered explanations that could be classified as relating to conventional physical science. A number of these responses $(N=16)$ were grouped together because they related to the earth's movement, for example: "There was an earthquake because the ground moved" and "The earth moved together." Another group of answers $(\mathbb{N}=15)$ in this category centered on the earth, or the world, shaking, for example: "The 
whole world shakes," and "The fault line moved and made the ground shake." Five children specified the earth or ground shifting, an example being: "The plates that make the world shift moved." Two children said that the earth cracked: "I don't know. The earth cracked." The group of subjects who gave these answers comprised 16 girls, 15 boys, and 5 other children whose sex was not recorded on the questionnaire. Further analysis of these 36 answers revealed that six of them could be considered to have some scientific basis, for example: "The fault line moved and made the ground shake." These answers came from 4 boys and 2 girls with an average age of 57 months.

In all, thirteen subjects gave explanations for the cause of the earthquake that fell in the category of spiritual or superhuman force. Seven children, 6 percent of the subjects, answered the question by saying that God, or Jesus, made the earthquake, and 1 child said that God could stop an earthquake One parent thought that the child attributed the earthquake to Father Nature, and one parent thought that the child would say that Mother Nature was the cause. One child said that "the devil did it."

A further category for explanations of the earthquake's cause was that of unusual physical science. There were 9 children in this category with an average age of 54 months. Two children said that volcanoes caused the earthquake, and 2 that water caused the earthquake. A child said: "When the water under the ground sloshes around it makes an earthquake." Gases under the earth was the explanation of two children in this category, one said bubbles, and one said that the earth needed to let some air out.

One subject, a boy aged 52 months, was recorded as attributing the earthquake to a bomb. 
The questionnaires from the remaining 21 children left the answer to this question blank.

From an assimilation-accommodation construct, an explanation of the limited understanding of the cause of earthquakes that is apparent in this data, might suggest that the subjects were placing the misunderstood, or vaguely understood, conceptual reality of the earthquake against the perceptual appearance of the damage at their homes. Parents' and teachers' explanations of basic scientific facts about earthquakes were apparently accommodated to existing structures, more than assimilated to new schemes, in many cases. A number of responses showed that the subjects believed that the effects of the earthquake preceded the cause. For example: "There was an earthquake because the ground moved". This data supported evidence of preoperational children's limited understanding of causality.

For other subjects, because the earthquake did not fit into existing cognitive structures, it was impossible to know what "rules" to apply, and hence they made up supernatural, magical, or animistic explanations about the cause of the earthquake. These subjects had a belief that something, or someone, had caused it. Neither should we discount the fact that some children may have had more understanding of the earthquake than was apparent in the anecdotal material, but were unable to express their beliefs.

The number of non-responses and "I don't know" responses might suggest that some children preferred not to think about the earthquake. This supports Dollinger's theory (1984) that young subjects experiencing a disaster favor "not thinking about it" as a coping mechanism. Some subjects may have experienced an alpha reaction (Ginsburg \& Opper, 1988), meaning that they 
were not sufficiently disturbed by the earthquake to search for new knowledge and make sense of the event.

Information as to what children thought about the effect of earthquakes (See Table 5, p. 88) was drawn from anecdotal material recorded by parents in answer to Question 2 in Part II of the questionnaire. This material is presented in Appendix C. When asked by a parent what might happen if there was another earthquake, 11 of the 21 children who had not responded to the question as to the cause of the earthquake did give an answer. These responses about the effect of an earthquake included the facts that objects would shake, fall, or break, the lights would go out, and that the child would go under a table. Analysis of the responses of the children who had stated that they did not know the cause of an earthquake revealed that 8 also responded that they did not know what would happen in another earthquake. Eighteen responses dealt with shaking and things falling down or being broken, for example: "The lamp would fall over again" and "It would knock all the stuff down again." In this group of answers, one child said that he would stop the earthquake, and one child said that people would get hurt.

Reviewing answers of the sixteen children who, in Question 1 of Part II, responded that the earth or the ground would move in an earthquake, revealed that 6 children said that the house would shake, and 9 children said that things would fall down. Five children said that the electricity would go off, and one said that the TV would go off. Six children said that they would go to a safe place. One child said that people would get hurt, and one that the bridge would fall down. Three children indicated their feelings about earthquakes, for 
example: "The ground shakes and we cuddle." One child stated that: "We will hide everything so it won't break."

Three of the 6 children who had an apparent element of scientific fact in their response about the cause of the earthquake, were recorded as expecting effects similar to those of the Loma Prieta earthquake in the event of another earthquake, for example: "Things will fall down and swing (light)." Three were concerned with safety, for example: "We hide under the big table." They expressed expectations of more violence than they had witnessed during the Loma Prieta earthquake, for example a boy aged 57 months suggested three effects of a future earthquake, namely that the house might fall down, that there would be landslides, and that the ground would split open. Another child, a boy aged 62 months said: "We could die." Altogether 5 children cited death as an effect of an earthquake, 4 boys and 1 girl, average age 57.4 months.

The other answers to the question relating to the effects of an earthquake recorded in Part II, Question 2, fit into the above categories. Effects such as things falling down, the house shaking, and hiding in a safe place were given.

Question 18 in Part I also produced data on the subjects' concepts of causality. It concerned the degree to which, following the earthquake, children associated shaking with an earthquake. Eighteen children were recorded as thinking that there was an earthquake every time they felt shaking. Their average age of $\mathbf{5 3 . 3}$ months was above the mean. Sixty four children, 61 percent of the subjects, sometimes associated shaking with the earthquake. Children's verbatim remarks showed that several of the subjects also associated certain noises with an earthquake, and one subject was reported as hiding under the kitchen table when she heard a loud airplane. 
This analysis of the subjects' concepts about the effect of future earthquakes indicated that preschool age children based their beliefs largely on past experience. For the most part, they were not able to make a cognitive leap into the realm of supposition. Whereas the subjects gave clear evidence of an assumption that a future earthquake would produce the same effects as the Loma Prieta earthquake, they also appeared to have picked up verbal or visual cues that damage could be more intense in a future earthquake. There may also have been allocentric thought on the part of some of the older children whose comments showed that they knew that effects could be different at another time. Several responses exhibited the preoperational characteristic of animism, indicating that the subjects believed that earthquakes had human attributes, such as sight. The high percentage of subjects who associated shaking with an earthquake indicated transductive reasoning built on a classification system with predictable properties. Thus, the subjects reasoned that, if an earthquake produced strong shaking, then every time there was strong shaking there was an earthquake. Transductive reasoning could also be present in many of the beliefs about future earthquakes, such as power outages, or the television not working. The number of subjects who were concerned with safety indicated that preschool children could think about disasterous events such as an earthquake, and that they had responded to the teachings of parents in acquiring knowledge about emergency procedures, following the Loma Prieta earthquake.

The data from Questions 14,15 , and 16 (see Appendix A) was analyzed to gain specific information as to where the subjects thought that the Loma Prieta earthquake had occurred, and thus to add more information to the data about 
children's understanding of the effect of earthquakes. A substantial percentage of the children (32\%), thought that the earthquake occurred universally. Their average age was 50.8 months. Twenty eight percent of the children, with an average age of 51.6 months, thought that whatever damage occurred at their house happened at everyone's house (See Table 6, p. 94). An ANOVA examining subjects' responses as a function of their chronological ages revealed that children who perceived the earthquake as occurring only at their own home were younger than those who realized it had struck more widely $(E=10.913, D<.05)$.

This data was consistent with the egocentric perspective that is a feature of preoperational thought. The intellectual immaturity of the younger subjects left them unable to see the earthquake from a global perspective. The data also supported the extent to which the subjects were limited by transductive reasoning. They apparently reasoned that, if there was an earthquake in one house, or city, then there must be an earthquake in every house, or every city.

Further data about children's concepts and cognitive awareness of the effects of earthquakes was obtained from responses to Questions 23, 24, and 25. This data was analyzed to assess what percentage of the subjects were concerned about what to do in the event of another earthquake. Results showed that 83 percent of the subjects $(N=85)$ were either unconcerned, or only a little concerned. Thirteen percent $(\mathrm{N}=14)$ were moderately concerned about what to do, and only 4 percent $(N=4)$ very much so. Parents were also asked to state an opinion as to whether they thought that their children were concerned with preparing for another earthquake. Data again showed that the majority of children were recorded as unconcerned, or as only a little concerned. Only 8 
percent of the subjects $(\mathrm{N}=8)$ were reported as being moderately concerned about making preparations, and 2 percent $(\mathrm{N}=2)$ as very much so. According to the data, the extent of damage in a future earthquake was of no concern to 65 percent of the subjects $(N=67)$. Twenty seven percent of the subjects $(N=28)$ were recorded as being a little concerned about the extent of damage in another earthquake, 8 percent $(\mathrm{N}=8)$ as moderately concerned, and one child was very concerned (See Table 7, p. 95).

Viewing all the data from answers to Questions 23, 24, and 25, showed that 32 percent of the subjects $(N=33)$ showed no concern at all about what to do in the event of another earthquake, preparing for another earthquake or the extent of damage that could occur. Thirty percent of the subjects $(\mathrm{N}=31)$, with an average age of 53.1 months, showed concern in two of these areas, and 24 percent $(\mathrm{N}=25)$ had at least a little concern in all areas.

From these results, it would appear that the majority of the subjects, due to the cognitive levels of preoperational thinking, were unaware of the full implications, or effects, of a major earthquake, although, in a pattern consistent with Handforth's research (1986), older children's concerns were more focused. The subjects' reaction pattern did not, therefore, fit an adult's typical response about the serious nature of earthquakes, nor did it exhibit a concern for earthquake preparedness.

\section{Hypothesis III}

Hypothesis III stated that the older, and therefore generally more cognitively aware, children were at the time of the earthquake, the less upset they would be by it. A simple regression predicting degree of disturbed sleep from age did not support the hypothesis $(I=.104, R>.05)$. 
Information about a disruption in regular eating habits showed that 13 percent of the youngest group, 10 percent of the four year olds, and 9 percent of the five year olds experienced some upset in this area (See Table 8, p. 96). A simple regression predicting degree of disruption in regular eating habits, likewise, did not support the hypothesis $(I=.012, p>.05)$.

Separation anxiety was also compared with chronological age (See Table 8, p. 98). A simple regression predicting degree of separation anxiety from age did not support the hypothesis $(\mathfrak{l}=.15, p<.05)$. Likewise, a simple regression predicting degree of being afraid to be alone in a room after the earthquake from age did not support the hypothesis $([=.11, R>.05)$. While each of these components of the overall measure of intensity of reaction was not statistically predicted by children's ages, age did nearly statistically significantly predict the composite variable, intensity of reaction $(r=186, p=.0581)$.

These results do not support the hypothesis that older children would be less upset by the earthquake. The oldest group of children, those 60 months or more, showed a markedly stronger intensity of reaction to the Loma Prieta earthquake than the younger subjects. One explanation for this behavior could be that the older children were better able to process, that is reflect on and interpret, the information they experienced, or received, about the earthquake. Piaget suggested that children of 4 and 5 years of age are capable of a type of logical reasoning known as semi-logic. Thus, the older the child, the more thorough the evaluative process. This prelogical thought led to reasoning about the reality of a natural disaster, and consequently to greater anxiety, rather than to the researcher's premise that, the more understanding of the event the lower 
the anxiety level. For younger children, the earthquake was apparently judged on the basis of appearance, leading to a lower intensity of reaction.

The intensity of reaction scores were recoded by sex. Further analysis of the data revealed that girls had an average intensity of reaction score of 15.5 , compared with 13.9 for boys (See Table 9, p. 97). A one-way ANOVA was performed using the 1-7 rating scale of distress at the time of the earthquake. Results confirmed findings that girls were more upset (mean girls' intensity of reaction 4.157, mean boys' intensity of reaction $3.22, E=5.94, p<.05$ ). Hypothesis IV

Hypothesis IV stated that there would be an optimum situation for the child to be in at the time of the earthquake to produce the least cognitive dissonance and affective distress. Analysis of the data from Question 1 giving information about who was with the child at the time of the earthquake revealed that 91 percent of the children $(\mathbb{N}=92)$ were with one or both parents, and for 13 percent of the subjects $(N=14)$ the whole family was together. Two percent of the subjects were with a baby sitter, 7 percent with other adults, including grandparents, and one child was with a friend.

Information about the whereabouts of each child at the time of the earthquake was obtained from the answers to Question 2. It was found that more than half the subjects were indoors at home, and a further 16 ouidoors at home. This data was studied to find the relationship between the whereabouts of each of the children at the time of the earthquake and their degree of upset. Dividing the subjects into quartiles, from least upset to most upset, according to intensity of reaction scores, the data about the intensity of reaction was compared with the data on the children's whereabouts at the time of the 
earthquake (See Table 10, p. 98). Of the sixty children who were indoors at home at the time of the earthquake, 63 percent were in the upper half of the intensity of reaction scores. For the children with the lowest grouping of scores, only 9 were indoors, and 44 percent were either outdoors at home, or at a park. Results of a one-way ANOVA showed, overall, a nearly statistically significant difference in the whereabouts of children and their intensity of reaction $(E=2.205, R<.0598)$. The Fisher PLSD confirmed that children who were at a park experienced the lowest intensity of reaction $(E=4.061, R<.05)$.

Data about the amount of damage at each of the children's homes was also compared with the intensity of reaction scores (See Table 11, p. 99). Again grouping the children from the least to the most intense reaction, it was found that the amount of damage that the homes sustained predicted the affective distress of the children $([=.289, R<.05)$. In the lowest grouping, 86 percent of the homes received only minor damage, whereas, considering the 25 percent of children with the most intense reaction to the earthquake showed that 57 percent of the homes received minor damage, whilst 38 percent of the children's homes received moderate damage.

Data about the emotional reactions of the caretakers at the time of the earthquake, obtained from answers to Question 22, was sorted in a range from very calm to distraught. Twenty-three percent of parents $(\mathrm{N}=24)$ recorded that they remained very calm at the time of the earthquake, and 32 percent $(N=33)$ that they were moderately calm. Twenty three percent $(\mathrm{N}=24)$ of the parents rated themselves as somewhat upset, and 22 percent $(\mathbb{N}=23)$ as visibly upset. One parent recorded a distraught reaction. Comparing parents' emotional reaction to the earthquake with their children's intensity of reaction scores 
showed that, when the parents were very calm, the children's reaction score was lower (See Table 12, p. 100). Results of a simple regression confirmed that the reaction of the parent predicted the intensity of reaction of the child $(I=.318$, $R<.05)$. The results of this comparison agreed with MCNamee's findings that children's response to stress is largely dependent on "the attitudes and actions of adults around them" (McNamee, 1982).

Parents also provided information about both their own and their child's emotional reaction to the earthquake in Part II of the questionnaire. This anecdotal material revealed that 21 percent $(\mathrm{N}=22)$ of the parents reported that, in their opinion, their child had been helped in coping with the effects of the earthquake because they, the parents, had remained calm and in control of the situation. Thirty six percent $(\mathrm{N}=37)$ of the parents thought that parents and family staying close had helped the coping process. The other significant coping strategy reported by parents was answering their children's questions and talking about the earthquake. Thirty seven percent $(\mathrm{N}=38)$ of the parents reported doing this. Several parents reported that they had made a game out of the earthquake, likening it to a roller coaster ride. Although parents reported this as a helpful coping strategy, Phillips noted that giving children misinformation may increase anxieties in children (Phillips, 1984). Parents also noted that neighborhood events, such as a baseball game later on the evening of the earthquake, or a barbecue with families in the immediate neighborhood, had aided the coping process.

The other variable considered in gathering data to measure the affective distress of the subjects following the Loma Prieta earthquake was the amount of exposure to information about the earthquake through TV viewing. In question 
20 parents were asked how much TV coverage of the earthquake their children had experienced. Sixteen percent $(\mathrm{N}=16)$ of the parents reported that their children had watched a great deal of television, and 27 percent $(\mathrm{N}=28)$ of the parents indicated that their children had watched a moderate amount. Seven percent $(N=7)$ of the parents noted that their children had not seen any earthquake coverage on TV and the remainder of the subjects $(50 \%)$ were reported as having seen a little of the TV coverage. The amount of TV each child viewed did not, however, significantly predict the intensity of reaction score $(I=.019,2>05)$.

In the grouping of children with the lowest intensity of reaction scores, only 2 had seen a great deal of TV. The children in the next lowest grouping on the scale showed 6 having watched a great deal of TV. Of the children ranked in the next to top grouping of intensity of reaction to the earthquake, 3 had seen a great deal of TV coverage, and the last group of subjects, those with the highest scores on the intensity of reaction scale, provided the following statistics: Five children had watched a great deal of TV, 7 had watched a moderate amount, 11 had watched a little, and 3 had not seen any coverage (See Table 13, p. 101).

Considering the results of this group of research questions confirmed the hypothesis that there would indeed be an optimum situation to cause the least affective distress for preschoolers at the time of an earthquake. Results showed that the best circumstances in which children could find themselves at the time of an earthquake would include being with an adult who remained calm. This corroborated research by Honig (1986b) who emphasized the need for a supportive adult to decrease stressor effects for preschoolers. Children whose homes received the least damage were generally less upset than those whose 
homes received major damage, and being outdoors, especially at a park, caused least affective distress. These results would appear to indicate that, where there was the least discongruent information for the child to process, then there was the least affective distress. Interestingly, there was not a strong relationship between the degree of upset and the amount of TV viewing. 


\section{CHAPTER FIVE}

\section{Conclusions}

This study investigated the extent of the relationship between preschoolaged children's cognitive developmental level and their cognitive and affective reactions to the Loma Prieta earthquake. Young children's concepts of causality were explored in a framework of the characteristics of preoperational thought. Emotional reactions to the earthquake were analyzed, and the coping skills employed by the subjects were studied. A summary of the results and conclusions of the study are described in this chapter.

\section{Summary of Results}

The first purpose of this study was to investigate whether the socialemotional coping strategies of preschool-aged children were delimited by their level of cognitive development. The expectation was that the subjects of this study would experience sleep and eating disturbances, and separation anxieties, in the days following the Loma Prieta earthquake. It was also hypothesized that, given their very limited understanding of the event, younger children would experience more affective distress than older children.

Results indicated that a substantial percentage of the subjects experienced disequilibrium due to the discrepancy between their experiences during the Loma Prieta earthquake, and their prior knowledge of such an event. This disequilibrium led to sleep disturbances and separation anxieties, although reports of disturbed eating habits were not significant. Thirty-nine percent of the subjects $(N=40)$ experienced disturbed sleep patterns for at least a few days, following the earthquake. For 11 percent of the subjects $(N=12)$, the disturbances lasted for more than a month. Fifty-five percent of the subjects 
$(N=56)$ experienced separation anxiety following the earthquake. Forty-six percent of the children $(\mathbb{N}=48)$ had difficulties separating from parents. This unease, however, only lasted for more than a week for 7 percent of the subjects. Forty-five percent of the subjects $(N=47)$ were unwilling to be left alone in a room at home on the day following the earthquake. This behavior lasted for more than a week for 11 percent of the subjects $(\mathrm{N}=12)$, and for more than a month for 6 percent of the subjects $(N=6)$. Comparing results in these areas of affective distress showed that sleep disturbances were exhibited for a longer time than separation anxieties, following the earthquake.

In order to investigate whether the intensity of subjects' reactions to the earthquake was age-related, an intensity of reaction score was formulated for each subject. The expectation was that the older, and therefore generally more cognitively aware, children were at the time of the earthquake, the less upset they would be by it. This did not prove to be so. The oldest group of subjects, with an age range of from 60-64 months, exhibited a significantly stronger intensity of reaction to the earthquake than the youngest subjects, whose age range was 36-39 months. The average reaction score for the oldest group was 20.8. For the youngest group it was 9 (average score $=15$ ). Statistical analysis of the data on affective distress showed that younger subjects did not experience more affective distress than older subjects.

Data analysis procedures produced a result showing a relationship between gender and intensity of reaction. The average intensity of reaction score for girls was 15.5 , compared with 13.9 for boys (average score $=15$ ). Girls also experienced more separation anxieties than boys, by a ratio of $5: 4$. 
The second purpose of the study was to explore concepts of causality in preschool-aged children through studying the subjects' beliefs about the cause and effects of an earthquake. Results were generally consistent with expectations. Children's remarks about the cause of the earthquake were found to fall into several broad categories. The first of these was conventional physical science. Thirty -five percent of the subjects $(\mathrm{N}=36)$ attributed the earthquake to the earth or the ground moving, for example: "There was an earthquake because the ground moved." Unusual physical science was the second category. Answers from these children, 9 percent of the subjects $(N=9)$, suggested that water, or gases, under the ground had caused the earthquake, or that it had been caused by a volcano. Another group of children's answers were in the category of spiritual or superhuman force. Twelve percent of the subjects $(\mathbb{N}=13)$ gave suggestions in this category, with concepts ranging from Mother Nature, to God, to the devil, as the cause of the earthquake. One child attributed the earthquake to a bomb, and one child termed it: "Just a party." Twenty-two percent of the subjects said: "I don't know" when asked what caused the earthquake. Their average age was 46.7 months. There was no response from 20 percent of the subjects.

Further information on preschool-aged children's concepts of causality was obtained form their verbatim remarks about the effects of an earthquake. In general, these remarks showed that the subjects had expectations of the effects of any future earthquake paralleling the effects of the Loma Prieta earthquake that they had experienced or witnessed. Effects of an earthquake enumerated by the subjects included: the house shaking, furniture and objects falling or breaking, the TV going off, and the lights going out. Twelve percent of the 
subjects ( $N=13$ ) did, however, expect more disasterous consequences from a future earthquake. They suggested that there could be more damage to their homes, that people could be hurt, and that people could die. Altogether 5 of the subjects cited death as an effect of an earthquake. Their average age was 57.4 months. Statements made by 24 percent of the subjects $(\mathrm{N}=25)$ showed a concern for safety. Their responses centered on either going outside, or going to a safe place in the house, in the event of an earthquake.

In the six months following the earthquake, 61 percent of the subjects $(N=62)$ sometimes attributed something shaking in their physical environment to an earthquake. Several of the subjects also associated certain noises with an earthquake, and one subject was reported as hiding under the kitchen table when she heard a loud airplane, several months after the earthquake. It is interesting to note that 90 percent of the subjects exhibited little or no concern about preparing for another earthquake.

The third purpose of this study was to examine variables that could affect children's ability to cope with an earthquake. It was predicted that there would be an optimum situation for children to be in at the time of the earthquake, one that would cause them the least cognitive dissonance and affective distress. This area of research showed some significant results. Some of these results were consistent with expectations, some of the findings were not. Children's whereabouts at the time of the earthquake was a factor in the degree of their intensity of reaction. Children who were outdoors at the time of the earthquake were, as a group, less distressed than those who were indoors. The subjects who were at parks at the time of the earthquake showed the least distress. The amount of damage that occurred at each of the subject's homes was the second 
variable to be compared to the intensity of reaction scores. It was found that the amount of damage that the homes sustained predicted the affective distress of the children.

Ninety-one percent of the subjects $(\underline{N}=92)$ were with one or both parents at the time of the earthquake. It was found that children exhibited less affective distress when parents remained calm. Data about the emotional reactions of the parents revealed that 23 percent of the parents $(N=24)$ recorded that they remained very calm at the time of the earthquake, and 32 percent $(\underline{N}=33)$ that they were moderately calm. Twenty-three percent of the parents $(N=24)$ rated themselves as somewhat upset, 22 percent $(\underline{N}=23)$ as visibly upset, and one as distraught. Statistical analysis showed that the reaction of the parent predicted the reaction of the child.

The last variable to be considered, in studying the intensity of reaction of the subjects, was the amount of TV coverage of the earthquake that had been viewed. Contrary to expectations, TV viewing was not a significant factor in the overall intensity of the subjects' reactions. Although 16 percent of the subjects $(\mathrm{N}=16)$ had watched "a great deal" of TV coverage of the earthquake, they were not significantly more upset than those who had watched none (7 percent).

\section{Discussion of Findings}

The questionnaire findings supported research (Rutter, 1981) showing that young children experience separation anxiety in stressful situations.

Characteristic attachment behaviors which tend to increase at times of stress, such as seeking close proximity to the parent, were recorded. The findings that a number of children did not want to sleep alone, following the Loma Prieta earthquake, and a significant percentage would not remain on their own in a 
room at their home, in the days following the earthquake, suggested affective distress resulting from cognitive dissonance. The data suggested that children's perceptual evaluations of the Loma Prieta earthquake led, in many cases, to an inability to assimilate or accommodate the experience. A parallel to this lack of cognitive adaption was reflected in the area of social cognition. The subjects' separation anxieties could also have arisen out of the fact that mental symbols became partly detached from the concrete experience of the earthquake, and were extended into fanciful concepts.

The children who suffered no emotional distress following the Loma Prieta earthquake may have failed to appreciate the contradictions of the earthquake stimuli. If their cognitive structures were not changed, then they would display no affective change. The reactions of more than half of the subjects experiencing emotional distress closely matched research showing that, when children experience acute stress as an isolated incident, there is only short-term imbalance between assimilation and accommodation, or vice-versa, and therefore emotional disturbance will be short-term (Honig, 1986a).

An unexpected outcome of this research was the discovery that girls experienced more nervous anxiety and affective distress than boys. This was not consistent with expectations. A possible explanation for this differential is that parents may have expected girls to be more fearful and distressed than boys, and they may, therefore, have been more attentive to girls' fears. A second possibility is that girls may have been more demonstrative in their verbalization of their fears.

Comparing children's verbatim responses to questions on causality showed that the their concepts about earthquakes displayed many of the characteristics 
of preoperational thought that have been enumerated in research. Rather than perceiving the conceptual reality of the event, the subjects in this study appeared to be limited either by a prelogical thought pattern based on the perceptual aspect of the event, or semi-logic combined with an intuitive way of thinking. It was further noted that, once an idea about the earthquake had been formulated, the subjects were unable to reverse their thinking. Children's ideas about the cause of an earthquake displayed both animism and magical thinking. Transductive thinking led them to over-generalize their experiences at the time of the earthquake, especially those concerning shaking and the power outage. Their ideas about where the earthquake occurred supported the evidence that, for preschool-aged children, concepts of physical causality are limited.

The analysis of the subjects' concepts about the effect of future earthquakes suggested that these preschool-aged children based their beliefs largely on past experience. For the most part, they were not able to make a cognitive leap into the realm of supposition. A minority of the subjects appeared to have picked up verbal or visual cues that damage could be more intense in a future earthquake. Whereas the majority of the subjects' views about the earthquake's effects exhibited an egocentric perspective, there may have been allocentric thought on the part of some of the older children whose remarks showed that they knew that effects could be different at another time. Several responses about the effects of earthquakes exhibited the preoperational characteristic of animism, indicating that the subjects believed that earthquakes had human attributes, such as sight. Four of the subjects' remarks referred to hiding from the earthquake. The fact that, following the earthquake, more than half the 
subjects associated shaking with an earthquake, indicated transductive reasoning built on a classification system with predictable properties. Transductive reasoning could also have been present in some of the beliefs about future earthquakes, such as the notion that the TV goes off in an earthquake. The remarks of subjects who were concerned with safety, or with what action to take in the event of an earthquake, indicated that some preschool-aged children can think about natural phenomena, such as an earthquake, and formulate coping skills and strategies.

The data pertaining to situational factors at the time of the Loma Prieta earthquake showed that there were indeed several variables that could have an impact on preschool-aged children at such a time. Not all these variables can be controlled at the time of a natural disaster, especially if the onset is sudden. Given warning and time to prepare, evidence gathered in this study suggested that preschoolers would fare best if they were outdoors, at a park, at the time of an earthquake. A variable that could, however, be controlled to a certain extent, would be the attitude and demeanor of the caregiver at such a time. Where adults could remain at least moderately calm, children would experience a lower level of anxiety and affective distress.

Parents reported that talking with children about the earthquake was a helpful tool in dealing with anxiety. Whereas this is a subjective opinion, research has shown it to be so. Involving children in clean-up, and earthquake preparedness activities, were also reported as helpful by parents. Analysis of the data, however, revealed children as having only minor interest in preparing for another earthquake. Because this activity would be therapeutic for the parents themselves, it raises the issue of to what extent parents can be accurate 
reporters of their own children's thoughts and behavior, and to what extent parents might project their own thoughts and feelings upon their children. Stephen Dollinger (1984), however, provided evidence that mothers were consistent in the reporting of their children's fearfulness. The possibility should be considered that children did not express an interest in clean-up and earthquake-preparedness activities because they favored "not thinking about it," or suppression, as a mode of coping (Dollinger, 1983). Although parents reported that "making a game" out of the earthquake, for example telling their children that it was a roller coaster ride, was helpful, research has shown that this is not necessarily a coping strategy that should be employed with preschool-aged children. When young children are working to understand discongruent information, it is harder for them to establish concepts if they receive misinformation (Phillips, 1984).

\section{Recommendations for Further Research}

The present study has addressed the issue of how a natural disaster, such as an earthquake, affects children who think at the preoperational level. Reading and research discussed in the previous chapters has led to the conclusion that the reactions of preschool-aged children to a natural disaster offers a wide field for further research. The disequilibrium that is an outcome of the discrepancy between young children's traumatic experiences and their prior knowledge offers an interesting perspective from which to examine assimilation and accommodation as adaptive strategies. The relationship between cognition and affective development also offers an interesting and important field for future research, because children's ways of coping with stress, when 
their predictable world becomes unpredictable, are profoundly affected by their cognitive structures.

Of paramount importance is the need for research into methods that parents and other adults can use to help preschool-aged children cope with a natural disaster. Children's coping skills are different at each developmental level, and the preoperational level has received less attention than the later stages. A practical guide, based on first hand knowledge and observation, could be used by parents and teachers, in helping preschool-aged children deal with their distress following a natural disaster. It could also be used to foster and enhance young children's ability to cope at such a time. 
REFERENCES 


\section{REFERENCES}

Aptekar, L., \& Boore, J. (1990). The emotional effects of disaster on children. The International Journal of Mental Health, 5(1).

Block, J. (1982). Assimilation, accommodation and the dynamics of personality development. Child Development, 53, 281-295.

Blom, G. E. (1986). A school disaster - intervention and research aspects. Journal of the American Academy of Child Psychiatry, 25(3), 336-345.

Bullock, M., \& Gelman, R. (1979). Preschool children's assumptions about cause and effect: Temporal ordering. Child Development, 50, 89-96.

Case. R. (1985). Intellectual development. Orlando: Academic Press.

Case. R. \& Khanna, F. (1981). The missing links: Stages in children's progression from sensorimotor to logical thought. In K. W. Fischer, (Ed.), New directions for child development: Cognitive development. San Fransisco: Jossey-Bass.

Chess, S. \& Thomas, A. (1986). Temperament in clinical practice. New York: Guilford Press.

Cowan, P. A. (1978). Piaget: With feeling. New York: Holt, Rinehart and Winston.

Damon, W. (1983). Social and personality development. New York: W. W. Norton.

Dollinger, S. J. (1983). Lightning-strike disaster among children. Unpublished manuscript, Southern Illinois University at Carbondale.

Dollinger, S. J., O'Donnell, J. P., \& Staley, A. A.. (1984). Lightning-strike disaster: Effects on children's fears and worries. Journal of Consulting and Clinical Psvchology, 52(6), 1028-1038.

Elkind, D. (1979). The child and seciety. New York: Oxford University Press.

Festinger, L. (1957). A theory of cognitive dissonance. Stanford, CA: Stanford University Press.

Fischer, K. W. (1980). A theory of cognitive development: The control and construction of hierarchies of skills. Psychological Review. 87, 477-531.

Flavell, J. (1977). Cognitive development. New Jersey: Prentice-Hall. 
Flavell, J. (1979). Metacognition and cognitive monitoring. American Psychologist. 34(10), 906-911.

Garmezy, N. (1981). Children under stress: Perspectives on antecedents and correlates of vulnerability and resistance to psychopathology. In I. A. Rabin, J. Aronoff, A. M. Barclay, \& R. A. Zucker (Eds.), Eurther explorations in personality. New York: Wiley.

Gelman, R. (1979). Preschool thought. American Psychologist, 34(10), 900905.

Ginsburg, H. P. \& Opper, S. (1988). Piaget's theory of intellectual development (3rd ed.). Englewood Cliffs: Prentice Hall.

Gruber, H. E. \& Voneche, J. J. (1977). The essential Piaget. New York: Basic Books.

Handford, H. A., Mayes, S. D., Mattison, R. E., Humphrey, F. J., Bagnato, S., Bixler, E. O., \& Kales, J. D. (1986). Child and parent reaction to the Three Mile Island nuclear accident. Journal of the American Academy of Child Psychiatry, 25(3), 346-356.

Honig, A. S. (1986a). Stress and coping in children (part 1). Young Children, 41(4), 51-63.

Honig, A. S. (1986b). Stress and coping in children (part 2). Young Children. 41(5), 47-59.

Hunt, J. M. (1961). Intelligence and experience. New York: Ronald.

Lazarus, R. S., \& Folkman, S. (1984). Stress, appraisal. and coping. New York: Springer.

Lystad, M. H. (1984). Children's responses to disaster: Family implications. International Journal of child Psychiatry, 5, 41-60.

McNamee, A., \& Stahl, E. (1982). Children and stress: Helping children cope. Washington, DC: Association for Childhood Education International.

Newman, C. J. (1976). Children of disaster: Clinical observations at Buffalo Creek. American Journal of Psychiatn, 133(3), 306-312.

Phillips, S. (1984). How children think. Unit for child studies (Selected papers number 30). Kensington, Australia: New South Wales University, School of Education. 
Piaget, J. (1950). The osychology of intelligence. New York: Harcourt Brace.

Piaget, J. (1951). The child's conception of the world. New York: The Humanities Press.

Piaget, J. (1962). Play, dreams and imitation in childhood. New York: W. W. Norton.

Piaget, J. (1966). The child's conception of physical causality. London: Routledge and Kegan Paul.

Piaget, J. (1967). Six psychological studies. New York: Random House.

Piaget, J. (1970). Genetic epistemelogy. New York: W. W. Norton.

Piaget, J. (1974). Understanding causality. New York: W. W. Norton.

Pines, M. (1983, November). Can a rock walk? Psychology Today, pp 46-54.

Pulaski, M. (1971). Understanding Piaget. New York: Harper \& Row.

Reimer, J., Paolitto, D. P., \& Hersh, R. H. (1979). Promoting moral growth: From Piaget to Kohlberg. New York: Longman.

Rutter, M. (1979). Protective factors in children's responses to stress and disadvantage. In M. W. Kent, \& J. A. Rolf (Eds.), Primary prevention of psychopathology: Vol. 3. Social competence in children. Hanover, NH: University Press of New England.

Rutter, M. (1981). Maternal deprivation reassed. Middlesex, England: Penguin.

San Fernando Valley Child Guidance Clinic. (1973). Coping with children's reaction to earthquakes and other disasters. (Available from San Fernando Valley Child Guidance Clinic, 9650 Zelzah Avenue, Northridge, CA 91325).

Selye, H. (1956). The stress of life. New York: McGraw-Hill.

Schaefer, Charles F. (1984). How to talk to children about really important things. New York: Harper \& Row.

Wadsworth, B. (1979). Piaget's theory of cognitive and affective development. New York: Longmans.

Zimbardo, P. G. (1988). Psychology and life. Glenview, Illinois: Scott, Foresman and Company. 
TABLES 
Table 1

Values Assigned Questionnaire ltems to Calculate Intensity of

Reaction Scores.

Questionnaire Item

Value

Question 6

Sleep disturbance

no $=0$

6b: $a=1, b=2, c=3, d=4$

Question 7

Eating disturbance

no $=0$

7b: $a=1, b=2, c=3, d=4$

Question 8

Willingness to be left alone

$$
\begin{aligned}
& i(a)=0, i i(a)=0, i i i(a)=0, \\
& i v(a)=0 \\
& i(b)=1, i i(b)=2, i i i(b)=3, \\
& i v(b)=4
\end{aligned}
$$


Table 1 continued

Questionnaire Item

Value

Question 9

Separation anxiety

$a=0, b=1, c=2, d=3, e=4$

Question 10

Resistance to school

$b=0, a=1$

Question 11

Resistance visiting friends

$b=0, a=1$

Part III, Question 1

Reaction to earthquake

$$
\begin{aligned}
& a=1-7 \\
& b=1-7 \\
& c=1-7
\end{aligned}
$$

Part III, Question 2

Reaction to aftershocks 
Table 2

Summary of Questionnaire Items Used for Data Analysis in Answering

Research Questions

Research Question

Items Used in

Data Analysis

1.1 What proportion of children

Question 6

experienced disturbed sleep

patterns following the

earthquake, and for how long?

1.2 What proportion of children

Question 7

experienced disturbed eating

habits following the

earthquake, and for how long?

1.3 What percentage of children

Questions 8-11

suffered separation anxieties

following the earthquake, and

for how long? 
Table 2 continued

Research Question

Items Used in

Data Analysis

2.1 What were children's

Question 1, Part II

concepts about the cause of

the earthquake?

2.2 What were the children's

Question 2, Part II concepts about the effects of the earthquake?

2.3 What were the children's

Questions 14-16

perceptions about the location of the Loma Prieta earthquake

in relationship both to their

own home, and to the world in general? 
Table 2 continued

$\begin{array}{ll}\text { Research Question } & \text { Items Used in } \\ \text { Data Analysis }\end{array}$

2.4 What was children's cognitive awareness about a future earthquake?

3.1 How did the children's ages relate to the degree of separation anxiety, and sleep and eating disturbances, following the earthquake?

\subsection{How did the children's} ages relate to their overall intensity of affective reaction to the earthquake?
Questions 23-25,

Part I

Question 2, Part II

Questions 6-9
Questions 6-11, Part I, Questions 1-2, Part III 
Table 2 continued

Research Question

Items Used in

Data Analysis

4.1 Where was each of the

Question 1

children participating in this

study at the time of the

earthquake?

4.2 How much damage did each

Question 4

of the children's homes sustain

at the time of the earthquake?

4.3 Were the children with

Question 2

their parents at the time of

the earthquake?

4.4 To what degree did the

Question 22, Part I,

children's caretakers remain

Question 3, Part III

calm at the time of the

earthquake? 
Table 2 continued

Research Question

Items Used in

Data Analysis

4.5 Did the amount of earthquake

Question 20

coverage on TV that the

children watched correlate

with their affective distress? 
Table 3

Distribution of Subjects' with Disturbed Sleep Patterns

Number of Children

Length of Disturbance

None

64

Few Days

23

Few Weeks

6

More Than a Month

9

Still Occurring

3

Note. No response recorded for one subject 
Table 4

Children Manifesting Affective Reactions to the Earthquake for a Week or Lenger

Reaction

Week Month 6 Months

Sleep disturbance

$\begin{array}{lll}16 & 11 & 3\end{array}$

Eating disturbance

4

0

0

Separation anxiety

15

8

1

Afraid to be alone

17

11

0

Note. Figures given are percentages of total population 
Table 5

Comparative Categorization of Subjects' Responses Relating to Causes and Effects of an Earthquake

$\overline{\text { Age }}$

Explanation of Cause

No Response

Concepts about Future Earthquake

No response

Similar to Loma Prieta

Concern for safety

"I don't know"
$20 \%$

$47.6 \quad 36-60$
$9 \%$

$7 \%$

$4 \%$

$1 \%$ 
Table 5 continued

\begin{tabular}{llll}
\hline & & \multicolumn{2}{c}{ Age } \\
\cline { 3 - 4 } & & Average Range \\
& & & \\
Explanation of Cause & & & $36-60$ \\
"I don't know" & $22 \%$ & 46.7 & \\
Concepts about Future Earthquake & & & \\
"I don't know" & $6 \%$ & & \\
Similar to Loma Prieta & $12 \%$ & & \\
Concern for safety & $3 \%$ & & \\
Fun & $1 \%$ & & \\
Could stop it & $1 \%$ & \\
\end{tabular}


Table 5 continued

\begin{tabular}{c} 
Age \\
\\
Average Range \\
\hline
\end{tabular}

Explanation of Cause

Conventional Physical Science $\quad 35 \% \quad 50.6 \quad 38-60$

Concepts about Future Earthquake

Repeat of Loma Prieta $\quad 21 \%$

Concern for safety $\quad 10 \%$

Worse consequences $\quad 5 \%$

Power off $5 \%$

People might be hurt or die $\quad 3 \%$

Hide things so won't break $\quad 2 \%$

No response $1 \%$ 
Table 5 continued

\begin{tabular}{c} 
Age \\
\\
Average Range \\
\hline
\end{tabular}

Explanation of Cause

$\begin{array}{llll}\text { Unusual Physical Science } & 8.5 \% & 54 & 43-64\end{array}$

Concepts about Future Earthquake

Concern with safety $\quad 3 \%$

People need help. Hurt/die 2\%

Similar effect to Loma Prieta $\quad 2 \%$

Earth would bounce $1 \%$

No response $1 \%$ 
Table 5 continued

Age

Average Range

Explanation of Cause

Spiritual or Superhuman force

$12 \%$

$50 \quad 36-59$

Concepts about Future Earthquake

Similar effect to Loma Prieta

$8 \%$

Concern with safety

$3 \%$

Would die if bigger

$1 \%$

"I don't know"

$1 \%$

Explanation of Cause

Bomb

$1 \%$

$52 \quad 52$

Concepts about Future Earthquake

People would die

$1 \%$ 
Table 5 continued

\begin{tabular}{ll}
\hline & \multicolumn{2}{c}{ Age } \\
& Average Range \\
\hline Explanation of Cause & \\
$\quad$ "It was just a party" & $1 \%$ \\
Concepts about Future Earthquake \\
Similar effect to Loma Prieta \\
and concern with safety
\end{tabular}

Note. Age range and average ages are in months. 
Table 6

Comparative Analysis of Subjects' Concepts of Earthquake's Location

Subjects Av. Age

Concept of Where Earthquake Occurred

Specific to one room in home

Specific to own home

Only in specific homes or buildings

Occurred universally

Whatever happened at child's home

happened at all homes
2

47.5

9

43.1

20

48.4

34

50.8

29

51.6

Note. Average ages are given in months. 
Table 7

Percentage of Subjects Showing Concerns About a Future Earthquake

Degree of Concern none little mod. high

\section{Children}

Categories of Concern

Concern about what to do if there is another earthquake

$45 \quad 43 \quad 13 \quad 4$

Concern about preparing for another earthquake

$\begin{array}{llll}62 & 32 & 8 & 2\end{array}$

Concern about the extent of damage that could occur in another earthquake

$\begin{array}{llll}68 & 28 & 8 & 1\end{array}$


Table 8

Sleep and Eating Disturbances and Separation Anxieties as a Function of Chronological Age

Age Range

\begin{tabular}{lccc}
\hline Sleep Eating & $\begin{array}{c}\text { Sep. } \\
\text { Anxiety }\end{array}$ & $\begin{array}{c}\text { Afraid to } \\
\text { be Alone }\end{array}$ & $\begin{array}{c}\text { Reaction } \\
\text { Score }\end{array}$ \\
\hline
\end{tabular}

$36-47$

$\begin{array}{llllll}\text { (Average } 41 \text { ) } & 42.5 \% & 12.5 \% & 27.5 \% & 35 \% & 11\end{array}$

48-59

$\begin{array}{llllll}\text { (Average 54) } & 33 \% & 10 \% & 19 \% & 54 \% & 15\end{array}$

60-64

$\begin{array}{llllll}\text { (Average 61) } & 64 \% & 9 \% & 55 \% & 64 \% & 21\end{array}$

Note. Ages are in months 


\section{Table 9}

Average Intensity of Reaction Scores as a Function of Subjects' Ages

\begin{tabular}{|c|c|c|}
\hline & Average Score & Average Age \\
\hline & 5 & 48 \\
\hline & 9.7 & 49.8 \\
\hline & 16.3 & 50.1 \\
\hline & 27 & 51.5 \\
\hline \multicolumn{3}{|c|}{$\begin{array}{ll}\text { Note. } & n=15 \\
& \text { Average ages in months }\end{array}$} \\
\hline \multicolumn{3}{|c|}{ Average Scores for Boys and Girls } \\
\hline Boys & 13.9 & \\
\hline Girls & 15.5 & \\
\hline
\end{tabular}


Table 10

Belationship Between Whereabouts of Subjects at the Time of the Earthquake and Intensitv of Reaction Scores

\begin{tabular}{|c|c|c|c|c|}
\hline Intensity of Reaction & 5 & 9.7 & 16.3 & 27 \\
\hline & \multicolumn{4}{|c|}{ Children } \\
\hline Indoors/home & 9 & 13 & 19 & 19 \\
\hline Outside/home & 5 & 5 & 3 & 3 \\
\hline In a car & 2 & 2 & & 1 \\
\hline At a park & 6 & 3 & 1 & \\
\hline Friend's house & & 1 & 1 & \\
\hline Other & 3 & 2 & 2 & 3 \\
\hline
\end{tabular}


Table 11

Comparison of Amount of Damage to Subjects' Homes and Intensity of Reaction Scores

\begin{tabular}{|c|c|c|c|c|}
\hline Intensity of Reaction & $\begin{array}{c}\text { Bottom } \\
\text { Quartile } \\
5\end{array}$ & $\begin{array}{c}\text { Second } \\
\text { Quartile } \\
9.7\end{array}$ & $\begin{array}{c}\text { Third } \\
\text { Quartile } \\
16.3\end{array}$ & $\begin{array}{c}\text { Top } \\
\text { Quartile } \\
27\end{array}$ \\
\hline & \multicolumn{4}{|c|}{ Children } \\
\hline Major & 1 & 0 & 1 & 0 \\
\hline Moderate & 1 & 4 & 5 & 10 \\
\hline Minor & 20 & 20 & 19 & 15 \\
\hline None & 3 & 2 & 0 & 1 \\
\hline No Answer & & & 1 & \\
\hline
\end{tabular}


Table 12

Comparison of Parents' Reaction to the Earthquake and their Children's

Beaction

\begin{tabular}{lcc}
\multicolumn{1}{c}{ Parent } & & Children \\
& & \\
Reaction & Percent & Average Intensity \\
& & of Reaction Score \\
& & 10 \\
\hline Very caim & 22 & 14 \\
Moderately Calm & 32 & 16 \\
Somewhat Upset & 22 & 17 \\
Visibly Upset & 21 & 31 \\
Distraught & 1 & \\
\hline
\end{tabular}

Note. $n=15$ 
Table 13

Amount of Earthquake Coverage seen on TV

\begin{tabular}{lcccc}
\hline & $\begin{array}{c}\text { Bottom } \\
\text { Quartile }\end{array}$ & $\begin{array}{c}\text { Second } \\
\text { Quartile }\end{array}$ & $\begin{array}{c}\text { Third } \\
\text { Quartile }\end{array}$ & $\begin{array}{c}\text { Top } \\
\text { Quartile }\end{array}$ \\
Intensity of Reaction & 5 & 9.7 & 16.3 & 27 \\
& & & & \\
\hline & & & & \\
Amount of TV & & Children & \\
None & & & & \\
Little & 15 & 13 & 13 & 11 \\
Moderate Amount & 8 & 6 & 7 & 7 \\
Great Deal & 2 & 6 & 3 & 5 \\
& & & & 3 \\
\hline
\end{tabular}


APPENDICES 
APPENDIX A

Cover Letters and Questionnaire 
April 2, 1990

Dear Teacher:

Thank you for agreeing to help me in conducting a study of the effects of the October, 1989 Loma Prieta earthquake on young children. The study will describe how their reaction to a disaster is limited by their level of cognitive development. The results should increase our knowledge of how young children deal with such new experiences and how they develop coping skills.

As you distribute the parent questionnaire in your classes I need you to make the following statement to the parents:

Would you please take this questionnaire home and spend fifteen minutes completing it? Please return it at our class session next week. Jane Farish is collecting information for her MA thesis at San Jose State University on young children's interpretation and handling of the Loma Prieta earthquake. The results will be described publicly, however they will be reported in terms of groups, not individuals, and any information that could be identified with you will remain anonymous and could only be disclosed as required by law. Please read the cover page entitled "Informed Participation Statement." Then, if you have any questions, call Jane at 247-8894.

Thank you again for your help. I will call you in a week and arrange to pick up the completed questionnaires.

Sincerely,

Jane Farish 
April 6, 1990

\section{Dear Parent:}

I need your help in conducting a study of the effects of the October, 1989 Loma Prieta earthquake on young children, and how their reaction to a natural disaster is limited by their level of cognitive development. The results of this study should increase our knowledge of how young children deal with such new experiences and how they develop coping skills.

Would you please spend 15 minutes to complete this questionnaire and return it to your teacher at your next class session? I am collecting this information for my MA thesis at San Jose State University, so I will be describing results publicly. However, results will be reported in terms of groups, not individuals, and any information that could be identified with you will remain anonymous and could only be disclosed as required by law.

If you have any questions about this study, I would be happy to talk with you. I can be reached at 247-8894. I hope that you will find time to help us in this research which may help us to a better understanding of how children's development results from the interplay of their experience and their maturational level.

Sincerely,

Jane Farish

Graduate Student 


\section{INFORMED PARTICIPATION STATEMENT}

\section{Principal Investigator: Project Title:}

Jane Farish, Graduate Student, Early Childhood Education Exploring the cognitive structures underlying young children's interpretation and handling of the Loma Prieta earthquake.

You are being asked to participate in a research study to investigate young children's interpretation of and reaction to the Loma Prieta earthquake. The results of this study should further our understanding of how young children deal with such new experiences and how they develop coping skills.

You should understand that:

(1) You are being asked to participate by completing a questionnaire that will focus on your child's reactions to the Loma Prieta earthquake. This questionnaire will take approximately 15 minutes to complete.

(2) The possible risk of this study is that there is a chance that you may feel uncomfortable in reflecting upon your child's experiences and reactions at that time.

(3) The possible benefits of this study to you are that results will be prescnted to your teachers to share with you. This information may be of interest and use to you as a parent enabling you to place your child's behavior in a broader context to better understand the nature of your child's reaction to the earthquake.

(4) The results from this study may be published, but any information from this study that can be identified with you will remain confidential and will be disclosed only with your permission or as required by law.

(5) Any questions about your participation in this study will be answered by Jane Farish (247-8894). Complaints about the questionnaire may be presented to Dr. Amy Strage (924-3715). For complaints about research subjects rights, or in the event of research related injury, contact Serena Stanford, PhD (Associate Academic Vice President for Graduate Studies \& Research) at 924-2480.

(6) Your consent to participate in this study is given voluntarily, without being coerced; you may refuse to participate in this study or in any part of it and you may withdraw at any time without prejudice to your relations with SJSU or Fremont Union High School District's Adult Education parenting programs.

(7) The completion and return of the questionnaire will be deemed your consent to participate in this research. 
Please return to: Jane Farish

714, Enright Avenue

Santa Clara

4082478894

Parent Questionnaire

Date of Birth of Child

Sex of Child: Male Female

\section{PART 1}

Please check the appropriate answer(s)

1. Where was your child during the earthquake?
a) indoors at home
b) outdoors at home
c) in a car
d) at a park
e) at a friend's house
f) other

2. Who was with your child at the time of the earthquake?
a) the whole family was together
b) one parent
c) one parent and siblings
d) babysitter
e) friend
f) other

3. Has your child experienced an earthquake before?
a) yes
b) no

4. How much damage did your house sustain?
a) major (structural) damage
b) moderate (overturned furniture) damage
c) minor (broken china \& glass) damage

5. If your child was not at home, how much damage did the place where he/she was sustain?

a) major damage

b) moderate damage

c) minor damage

6. Were your child's sleep patterns disturbed after the earthquake?

a) yes

b) no (If no, continue to question 7)

For how long were the sleep patterns disturbed?
a) a few days
b) a few weeks
c) more than a month
d) still disturbed

7. Were your child's eating habits disturbed after the earthquake?

a) yes

b) no (If no, continue to question 8)

For how long were the eating habits disturbed? 


\author{
a) a few days \\ b) a few weeks \\ c) more than a month \\ d) still disturbed
}

8. Was your child willing to be left alone in a room

i) on the day after the earthquake

a) yes

b) no

ii) in the week following the earthquake

a) yes

b) no

iii) during the month following the earthquake

a) yes

b) no

iv) more than one month following the earthquake

a) yes

b) no

9. Did your child suffer separation anxiety (other than his/her normal behavior) following the earthquake

a) not at all

b) for a few days

c) for a week

d) for a month

e) still occuring

10. Did your child resist going to school at any time in the week following the earthquake?
a) yes

b) no

11. Did your child resist visiting friends' homes at any time in the week following the earthquake?

$$
\text { a) yes }
$$

12. Does your child play earthquake related games since October 17?

$$
\text { a) yes }
$$

b) no

13. Does your child mix fantasy and reality in playing/talking about earthquakes?

$$
\text { a) yes }
$$

b) no 
14. Did your child think that the earthquake occured

i) only at his/her own home

a) yes

b) no

ii) only in specific homes or buildings

a) yes

b) no

iii) universally (outside of the actual earthquake area)

a) yes

b) no

15. Did your child perceive the earthquake as specific to one room at home? (e.g. It only occured in the kitchen)
a) yes
b) no

16. Did your child think that whatever happened at your house happened at all houses? (e.g. If your TV broke, then all TVs broke)
a) yes
b) no

17. Was your child upset by the aftershocks
a) less than by the earthquake
b) more than by the earthquake
c) the reaction was equal

18. When your child experiences something shaking now, does he/she think that it is an earthquake?
a) yes, every time
b) sometimes
c) no

19. Has your child conceptualized any of the events of October 17 in reverse order? (e.g. The bookcase fell, and then there was an earthquake)
a) yes
b) no

20. How much earthquake coverage did your child see on TV?
a) a great deal (TV on all the time)
b) a moderate amount (several hours)
c) a little
d) none

21. How affected was your child by the TV coverage that he/she saw?
a) very upset
b) somewhat upset
c) interested, but not upset
d) disinterested

22. At the time of the earthquake were you, as a parent,
a) very calm
b) moderately calm
c) somewhat upset
d) visibly upset 


\section{e) distraught}

23. Is your child concerned about what to do if there is another earthquake?
a) no
b) yes, a little
c) yes, moderately
d) very much so

24. Is your child concerned about preparing for another earthquake?
a) no
b) a little
c) moderately
d) very much so

25. Is your child concerned about the extent of damage that could occur in another earthquake?
a) no
b) a little
c) moderately
d) very much so 
PART II

Please answer the following questions

1. What would your child say if asked: Why was there an earthquake? or What made it happen?

2. What would your child say if asked what might happen if there is another earthquake?

3. What helped your child cope with the earthquake?

4. What information about earthquakes was imparted to your child after the October 17 earthquake by you, teachers, others?

\section{PART III}

Please circle the appropriate number

$1=$ no apparent distress

$7=$ extremely upset

1. Considering your child's normal disposition, on a scale of 1-7 how upset was your child

a) at the time of the earthquake

1234567

b) the day after the earthquake

$\begin{array}{lllllll}1 & 2 & 3 & 5 & 6 & 7\end{array}$

c) a week later

1234567

2. On a scale of 1-7 how upset was your child by the aftershocks?

1234567

Please feel free to use the back of this for any further comments, or anecdotes that you would like to share. 


\section{APPENDIX B}

Children's responses to Question 1, Part II 
What would your child say if asked: Why was there an earthquake? or What made it happen?

\begin{tabular}{|c|c|c|c|}
\hline Subject & Age & Sex & Verbatim Answer \\
\hline 1 & 52 & boy & A bomb dropped. \\
\hline 2 & 43 & girl & The house shakes. \\
\hline 3 & 53 & girl & Because Jesus made it come. \\
\hline 4 & 55 & boy & Because God made it. \\
\hline 5 & 56 & boy & Because of a crack in the earth. \\
\hline 6 & 50 & boy & no response \\
\hline 7 & 55 & girl & $\begin{array}{l}\text { It's water under the street and under the } \\
\text { ground that wiggles. It sloshes around } \\
\text { and makes the ground move. When the } \\
\text { water under the ground sloshes around } \\
\text { it makes an earthquake. }\end{array}$ \\
\hline 8 & 57 & boy & $\begin{array}{l}\text { I don't know and I don't want to talk } \\
\text { about it. }\end{array}$ \\
\hline 9 & 48 & girl & $\begin{array}{l}\text { Bubbles underground come up and } \\
\text { shakes. }\end{array}$ \\
\hline
\end{tabular}


Appendix B continued

\begin{tabular}{|c|c|c|c|}
\hline Subject & Age & Sex & Verbatim Answer \\
\hline 10 & 43 & girl & $\begin{array}{l}\text { Well I think the earth just shaked a lot. It } \\
\text { was really an accident but we just } \\
\text { thought it was on purpose. Maybe the } \\
\text { Japanese people wanted to start a war } \\
\text { and they did it on purpose. I told her that } \\
\text { the Japanese people are our friends and } \\
\text { they are peaceful. She said: Well they } \\
\text { have those long pokey things to poke } \\
\text { people with. I realized that she was } \\
\text { talking about the Samurai swords we } \\
\text { saw recently in Shogun restaurant. }\end{array}$ \\
\hline 11 & 58 & boy & Parts of the earth were shifting. \\
\hline 12 & 36 & boy & God made it happen. \\
\hline 13 & 40 & girl & no response \\
\hline 14 & 58 & girl & no response \\
\hline 15 & 58 & girl & I don't know why it happened. \\
\hline 16 & 41 & girl & no response \\
\hline 17 & 38 & girl & The earth shook. \\
\hline
\end{tabular}


Appendix B continued

\begin{tabular}{llll}
\hline Subject & Age & Sex & Verbatim Answer \\
\hline 18 & & & \\
& 39 & girl & $\begin{array}{l}\text { There was an earthquake because the } \\
\text { ground moved. Pressure would build up } \\
\end{array}$ \\
& & & under the soil. \\
19 & 45 & girl & no response \\
20 & 44 & boy & I don't know. Why? \\
21 & 38 & girl & I don't know. \\
22 & 38 & girl & I don't know. \\
23 & 60 & girl & I don't know. \\
24 & 60 & girl & I don't know. The earth cracked. \\
25 & 59 & boy & no response \\
26 & 60 & girl & The earth shook. \\
27 & 59 & boy & A mountain shook like a volcano. \\
28 & 40 & boy & Because they're real. Like when in \\
& & & Wonderland (at Happy Hollow) this big \\
& & & caterpillar can break houses. \\
29 & 59 & boy & His answer would be about Mother \\
& & & Nature.
\end{tabular}


Appendix B continued

\begin{tabular}{|c|c|c|c|}
\hline Subject & Age & Sex & Verbatim Answer \\
\hline 30 & 64 & boy & $\begin{array}{l}\text { Well ... it's... I'm not real sure. But the } \\
\text { gases under the ground get real hot and } \\
\text { explode and the ground moves. What } \\
\text { are gases? }\end{array}$ \\
\hline 31 & 36 & boy & Jesus made the earthquake. \\
\hline 32 & 45 & girl & $\begin{array}{l}\text { The trees shook and the roots shook } \\
\text { because the rumbling like a cone in went } \\
\text { on for a long time like an hour or so. the } \\
\text { ground starts to shake. When the roots } \\
\text { of the trees shake it makes the world } \\
\text { shake. }\end{array}$ \\
\hline 33 & 56 & boy & The ground moved together. \\
\hline 34 & 58 & boy & $\begin{array}{l}\text { He might attribute it to the earth moving, } \\
\text { or he might make up something } \\
\text { fantastical. }\end{array}$ \\
\hline 35 & 51 & boy & $\begin{array}{l}\text { Because the under surface of the earth } \\
\text { was changing. }\end{array}$ \\
\hline 36 & 43 & boy & I don't know. \\
\hline 37 & 51 & boy & I don't know. I think the devil did it. \\
\hline 38 & 53 & boy & The whole world shakes. \\
\hline
\end{tabular}


Appendix B continued

\begin{tabular}{|c|c|c|c|}
\hline Subject & Age & Sex & Verbatim Answer \\
\hline 39 & 57 & boy & $\begin{array}{l}\text { There is gas under earth, and when it } \\
\text { boils the whole world shakes or God } \\
\text { stops it. }\end{array}$ \\
\hline 40 & 62 & boy & Maybe the plates moved. \\
\hline 41 & 43 & girl & $\begin{array}{l}\text { Water from neighbor's swimming pool } \\
\text { made it happen. Everything breaks. }\end{array}$ \\
\hline 42 & 60 & girl & I don't know. \\
\hline 43 & & boy & no response \\
\hline 44 & 47 & girl & I don't know. \\
\hline 45 & 42 & girl & The ground shakes. \\
\hline 46 & 47 & boy & I don't know. \\
\hline 47 & 53 & boy & $\begin{array}{l}\text { Probably what his older brother says } \\
\text { whose seven, Father Nature got mad. }\end{array}$ \\
\hline 48 & 53 & boy & no response \\
\hline 49 & 56 & girl & God \\
\hline 50 & 42 & girl & The ground is shifting. \\
\hline 51 & 59 & girl & Because God shaked the ground. \\
\hline 52 & 52 & boy & Jesus and the ground made it happen. \\
\hline 53 & 41 & boy & The earth needed to shake. \\
\hline 54 & 52 & boy & no response \\
\hline 55 & 48 & girl & The earth shook. \\
\hline
\end{tabular}


Appendix B continued

\begin{tabular}{|c|c|c|c|}
\hline Subject & Age & Sex & Verbatim Answer \\
\hline 56 & 54 & girl & She didn't want to talk about it. \\
\hline 57 & 58 & girl & I don't know. \\
\hline 58 & 57 & boy & $\begin{array}{l}\text { The fault line moved and made the } \\
\text { ground shake. }\end{array}$ \\
\hline 59 & 55 & girl & $\begin{array}{l}\text { Because the ground rubbed against } \\
\text { each other. }\end{array}$ \\
\hline 60 & 39 & boy & I don't know. \\
\hline 61 & 44 & girl & no response \\
\hline 62 & 61 & boy & I don't know. \\
\hline 63 & 58 & boy & no response \\
\hline 64 & 54 & 54 & The earth moved. \\
\hline 65 & 36 & 36 & no response \\
\hline 66 & 50 & boy & no response \\
\hline 67 & 39 & boy & I don't know. \\
\hline 68 & 42 & girl & no response \\
\hline 69 & 49 & girl & Something rolled under the earth. \\
\hline 70 & 52 & boy & I don't know. \\
\hline 71 & 47 & girl & $\begin{array}{l}\text { She thought a giant was coming to get } \\
\text { her. }\end{array}$ \\
\hline 72 & 42 & girl & The earth shook. The ground moved. \\
\hline 73 & 36 & girl & no response \\
\hline
\end{tabular}


Appendix B continued

\begin{tabular}{|c|c|c|c|}
\hline Subject & Age & Sex & Verbatim Answer \\
\hline 74 & 56 & girl & I don't know. \\
\hline 75 & 50 & & The earth was shaking and broke. \\
\hline 76 & 53 & girl & The earth needed to move. \\
\hline 77 & 53 & & The rocks hit each other and move. \\
\hline 78 & 51 & & The ground was all shook up. \\
\hline 79 & 54 & & The ground moved. \\
\hline 80 & 54 & boy & The earth moves. \\
\hline 81 & 47 & girl & I don't know. \\
\hline 82 & 62 & boy & $\begin{array}{l}\text { Two pieces of the earth move, makes } \\
\text { everything on it move. The earth is } \\
\text { growing all the time. }\end{array}$ \\
\hline 83 & 36 & girl & no response \\
\hline 84 & 55 & boy & Probably the ground shook. \\
\hline 85 & 58 & girl & The earth needs to move sometimes. \\
\hline 86 & 51 & boy & it was just a party. \\
\hline 87 & 43 & boy & The ground shakes. \\
\hline 88 & 55 & girl & I don't know. \\
\hline 89 & 42 & boy & $\begin{array}{l}\text { Cause the earth moved. It just } \\
\text { happened. }\end{array}$ \\
\hline 90 & 61 & boy & no response \\
\hline
\end{tabular}


Appendix $B$ continued

\begin{tabular}{|c|c|c|c|}
\hline Subject & Age & Sex & Verbatim Answer \\
\hline 91 & 54 & girl & $\begin{array}{l}\text { I don't know. She thought someone she } \\
\text { knew was shaking the house. }\end{array}$ \\
\hline 92 & 52 & girl & no response \\
\hline 93 & 47 & girl & I don't know. \\
\hline 94 & 57 & boy & I don't know. \\
\hline 95 & 58 & girl & The earth shaked. \\
\hline 96 & 37 & girl & Probably nuclear. \\
\hline 97 & 55 & girl & $\begin{array}{l}\text { The plates that make the world shift } \\
\text { moved. }\end{array}$ \\
\hline 98 & 45 & boy & $\begin{array}{l}\text { The earth quaked way down deep in the } \\
\text { ground. }\end{array}$ \\
\hline 99 & 58 & boy & $\begin{array}{l}\text { Cuz the earth needed to let some air out. } \\
\text { Because if the earth holded it in, it would } \\
\text { explode. The earth would explode and } \\
\text { everyone would die. }\end{array}$ \\
\hline 100 & 48 & & The earth moved or the ground moved. \\
\hline 101 & 42 & girl & no response \\
\hline 102 & 55 & boy & I don't know. \\
\hline 103 & 40 & boy & Because the earth is moving. \\
\hline
\end{tabular}


Appendix B continued

\begin{tabular}{llll} 
Subject & Age & Sex & Verbatim Answer \\
\hline 104 & 60 & boy & no response \\
105 & 36 & girl & I don't know. Why? \\
106 & 52 & boy & Because there's volcanoes and \\
& & & volcanoes make it work.
\end{tabular}

Note. Ages are in months

Italics indicate parents' words 
APPENDIX C

Children's responses to Question 2, Part II 
What would your child say if asked what might happen if there is another earthquake?

\begin{tabular}{|c|c|c|c|}
\hline Subject & Age & Sex & Verbatim Answer \\
\hline 1 & 52 & boy & People would die. \\
\hline 2 & 43 & girl & The power goes out. The TV goes off. \\
\hline 3 & 53 & girl & $\begin{array}{l}\text { Some things will break, some things will } \\
\text { break. If its glass it will break. If it is a } \\
\text { big one everything will fall down. }\end{array}$ \\
\hline 4 & 55 & boy & $\begin{array}{l}\text { The whole ground would break. We } \\
\text { would die if it was bigger. }\end{array}$ \\
\hline 5 & 56 & boy & $\begin{array}{l}\text { He'd probably go through an } \\
\text { explanation of how chandeliers sway, } \\
\text { tapes topple and everything shakes. He } \\
\text { might go on to explain some of the real } \\
\text { damage he knows about, likes freeways } \\
\text { collapsing, chimneys falling, etc. }\end{array}$ \\
\hline 6 & 50 & boy & The lights will go out. \\
\hline
\end{tabular}


Appendix C continued

\begin{tabular}{|c|c|c|c|}
\hline Subject & Age & Sex & Verbatim Answer \\
\hline 7 & 55 & girl & $\begin{array}{l}\text { When there's a big earthquake she is } \\
\text { going to go under her bed, or in the } \\
\text { hallway or urder a table and when it is } \\
\text { all over, she is going to go out and play. }\end{array}$ \\
\hline 8 & 57 & boy & $\begin{array}{l}\text { Probably I don't know and I don't want to } \\
\text { talk about it. }\end{array}$ \\
\hline 9 & 48 & girl & $\begin{array}{l}\text { Fragile things fall down and break. } \\
\text { Glass breaks. }\end{array}$ \\
\hline 10 & 43 & girl & $\begin{array}{l}\text { Maybe it will damage our house if it is a } \\
\text { ninety pointer. If we hid under a bed and } \\
\text { we grabbed the china we would be safe. } \\
\text { But our room would be a mess again. }\end{array}$ \\
\hline 11 & 58 & boy & $\begin{array}{l}\text { Things would fall down. (Trees, rooi, } \\
\text { furniture). }\end{array}$ \\
\hline 12 & 36 & boy & $\begin{array}{l}\text { He would say that the ground would } \\
\text { move. }\end{array}$ \\
\hline 13 & 40 & girl & $\begin{array}{l}\text { She would discuss what she would do } \\
\text { for protection - duck under the desk at } \\
\text { home, etc. }\end{array}$ \\
\hline
\end{tabular}


Appendix $\mathrm{C}$ continued

\begin{tabular}{|c|c|c|c|}
\hline Subject & Age & Sex & Verbatim Answer \\
\hline 14 & 58 & girl & no response \\
\hline 15 & 58 & girl & I don't know. \\
\hline 16 & 41 & girl & no response \\
\hline 17 & 38 & girl & The house would shake. \\
\hline 18 & 39 & girl & $\begin{array}{l}\text { She would cry. Her brother would grab } \\
\text { her and run under the table. }\end{array}$ \\
\hline 19 & 45 & girl & $\begin{array}{l}\text { She would say the earth shook and } \\
\text { everything moved. }\end{array}$ \\
\hline 20 & 44 & boy & It would knock all the stuff down again. \\
\hline 21 & 38 & girl & $\begin{array}{l}\text { I want the earthquake to come again. } \\
\text { Why? Because it was fun. I like it. }\end{array}$ \\
\hline 22 & 38 & girl & The lamp would fall over again. \\
\hline 23 & 60 & girl & Some more things will break. \\
\hline 24 & 60 & girl & $\begin{array}{l}\text { The house would shake. I would be } \\
\text { frightened. I would start running for } \\
\text { under the table or to the strongest place } \\
\text { in the house. }\end{array}$ \\
\hline
\end{tabular}


Appendix $\mathrm{C}$ continued

\begin{tabular}{|c|c|c|c|}
\hline Subject & Age & Sex & Verbatim Answer \\
\hline 25 & 59 & boy & $\begin{array}{l}\text { Get under the table and everything } \\
\text { would shake. Some things would break. } \\
\text { All the lights would turn off. You would } \\
\text { lose some things. }\end{array}$ \\
\hline 26 & 60 & girl & Things would fall down. \\
\hline 27 & 59 & boy & $\begin{array}{l}\text { People would get hurt or die. Buildings } \\
\text { would get hurt. }\end{array}$ \\
\hline 28 & 40 & boy & $\begin{array}{l}\text { I won't get mixed up and go outside. I'll } \\
\text { know to go right under the big table. }\end{array}$ \\
\hline 29 & 59 & boy & Our house will move up and down again. \\
\hline 30 & 64 & boy & $\begin{array}{l}\text { We hide under the big table away from } \\
\text { the fireplace. Then leave and go outside } \\
\text { away from the trees. }\end{array}$ \\
\hline 31 & 36 & boy & $\begin{array}{l}\text { Get under the table. Use our } \\
\text { emergencies supplies. }\end{array}$ \\
\hline 32 & 45 & girl & $\begin{array}{l}\text { I'd run under a table so nothing would } \\
\text { fall on me. I have to go outside at school } \\
\text { to the grass, or run to the teacher and } \\
\text { she'd show us where to go, or stand in a } \\
\text { doorway. }\end{array}$ \\
\hline
\end{tabular}


Appendix C continued

\begin{tabular}{|c|c|c|c|}
\hline Subject & Age & Sex & Verbatim Answer \\
\hline 33 & 56 & boy & The tables would move. \\
\hline 34 & 58 & boy & $\begin{array}{l}\text { He'd probably say that the house would } \\
\text { get "messed up" - things falling out of } \\
\text { cupboards, etc. In other words, } \\
\text { everything that happened in October. }\end{array}$ \\
\hline 35 & 51 & boy & $\begin{array}{l}\text { The TV would be broken. The house } \\
\text { would be fallen. }\end{array}$ \\
\hline 36 & 43 & boy & $\begin{array}{l}\text { There would be a lot of shaking and a lot } \\
\text { of noise. }\end{array}$ \\
\hline 37 & 51 & boy & $\begin{array}{l}\text { We'd hide under the table. Maybe the } \\
\text { TV would fall over again. }\end{array}$ \\
\hline 38 & 53 & boy & $\begin{array}{l}\text { The chimney will fall down. I asked him } \\
\text { what might happen inside and he } \\
\text { responded: "Nothing. We would hide } \\
\text { everything in a strong place so it } \\
\text { wouldn't break. }\end{array}$ \\
\hline 39 & 57 & boy & no response \\
\hline 40 & 62 & boy & $\begin{array}{l}\text { I would zoom to the doorway. The whole } \\
\text { world would go - rrrrrr. He then spun } \\
\text { around wildly and fell to the floor. }\end{array}$ \\
\hline
\end{tabular}


Appendix $\mathrm{C}$ continued

\begin{tabular}{|c|c|c|c|}
\hline Subject & Age & Sex & Verbatim Answer \\
\hline 41 & 43 & girl & We will wait outside. \\
\hline 42 & 60 & girl & I don't know. \\
\hline 43 & & boy & I don't know. \\
\hline 44 & 47 & girl & I don't know. \\
\hline 45 & 42 & girl & The bookcase with TV would fall over. \\
\hline 46 & 47 & boy & $\begin{array}{l}\text { That he should get under a table and } \\
\text { that things would fall down and the } \\
\text { electricity would go out. And that he } \\
\text { should grab his baby sister if I'm not in } \\
\text { the room. }\end{array}$ \\
\hline 47 & 53 & boy & $\begin{array}{l}\text { The TV might fall down. The glasses } \\
\text { might break. }\end{array}$ \\
\hline 48 & 53 & boy & $\begin{array}{l}\text { The lamp will tip over and the house will } \\
\text { shake. }\end{array}$ \\
\hline 49 & 56 & girl & $\begin{array}{l}\text { Things might fall down. The house } \\
\text { would shake. }\end{array}$ \\
\hline 50 & 42 & girl & $\begin{array}{l}\text { It would shake our house. I would go in } \\
\text { the safe area of room. }\end{array}$ \\
\hline 51 & 59 & girl & I don't know. \\
\hline
\end{tabular}


Appendix C continued

\begin{tabular}{|c|c|c|c|}
\hline Subject & Age & Sex & Verbatim Answer \\
\hline 52 & 52 & boy & $\begin{array}{l}\text { If there's a little one nobody will feel it. If } \\
\text { its a big one a house might fall down. }\end{array}$ \\
\hline 53 & 41 & boy & Things will crash. \\
\hline 54 & 52 & boy & $\begin{array}{l}\text { The bookcases might fall. The windows } \\
\text { might break. }\end{array}$ \\
\hline 55 & 48 & girl & The trees might fall down. \\
\hline 56 & 54 & girl & no response \\
\hline 57 & 58 & girl & The building would shake. \\
\hline 58 & 57 & boy & $\begin{array}{l}\text { The house might fall down. Landslides. } \\
\text { The ground splits open. }\end{array}$ \\
\hline 59 & 55 & girl & Things will fall down and swing. \\
\hline 60 & 39 & boy & He would name the safe places to go. \\
\hline 61 & 44 & girl & no response \\
\hline 62 & 61 & boy & Things would fall down. \\
\hline 63 & 58 & boy & no response \\
\hline 64 & 54 & girl & $\begin{array}{l}\text { That everything shakes, things fall, it's } \\
\text { noisy. }\end{array}$ \\
\hline 65 & 36 & girl & no response \\
\hline 66 & 50 & boy & Run out of the house and quick. \\
\hline 67 & 39 & boy & I don't know. \\
\hline
\end{tabular}


Appendix C continued

\begin{tabular}{|c|c|c|c|}
\hline Subject & Age & Sex & Verbatim Answer \\
\hline 68 & 42 & girl & no response \\
\hline 69 & 49 & girl & $\begin{array}{l}\text { Someone will die and get hurt. } \\
\text { Someone's house will break. Someone } \\
\text { would need help, food and water and } \\
\text { bandages. }\end{array}$ \\
\hline 70 & 52 & boy & The house would shake. \\
\hline 71 & 47 & girl & Things fall down. \\
\hline 72 & 42 & girl & $\begin{array}{l}\text { The books would fall down when the } \\
\text { earth shakes again. }\end{array}$ \\
\hline 73 & 36 & girl & no response \\
\hline 74 & 56 & girl & Shaked up. \\
\hline 75 & 50 & & We will go under the big desk. \\
\hline 76 & 53 & giri & We get under a table or doorway. \\
\hline 77 & 53 & & The ground shakes and we cuddle. \\
\hline 78 & 51 & & I'll go under my desk or table. \\
\hline 79 & 54 & & no response \\
\hline 80 & 54 & boy & $\begin{array}{l}\text { The house would shake. We would go } \\
\text { into the hall. The lights would go out. } \\
\text { We'd go outside. There will be more } \\
\text { shaking. }\end{array}$ \\
\hline
\end{tabular}


Appendix C continued

\begin{tabular}{|c|c|c|c|}
\hline Subject & Age & Sex & Verbatim Answer \\
\hline 81 & 47 & girl & Go under the table. \\
\hline 82 & 62 & boy & We could die. \\
\hline 83 & 36 & girl & It will be only at our house. \\
\hline 84 & 55 & boy & The lights would go out. \\
\hline 85 & 58 & girl & Run to Mommy. \\
\hline 86 & 51 & boy & $\begin{array}{l}\text { Things will fall down and everything will } \\
\text { shake and you have to get under the } \\
\text { table. }\end{array}$ \\
\hline 87 & 43 & boy & $\begin{array}{l}\text { I would be scared. l'd go under my bed. } \\
\text { The house would shake and we'd all run } \\
\text { outside. }\end{array}$ \\
\hline 88 & 55 & girl & Everything will fall down. \\
\hline 89 & 42 & boy & $\begin{array}{l}\text { All my stuff fall over and I might have to } \\
\text { clean up all stuff. And the bridge fall } \\
\text { down. }\end{array}$ \\
\hline 90 & 61 & boy & Things would shake. Things might fall. \\
\hline 91 & 54 & girl & $\begin{array}{l}\text { Trees might fall down. Plants and things } \\
\text { might get broken. }\end{array}$ \\
\hline
\end{tabular}


Appendix C continued

\begin{tabular}{|c|c|c|c|}
\hline Subject & Age & Sex & Verbatim Answer \\
\hline 92 & 52 & girl & $\begin{array}{l}\text { Things might fall down. People might be } \\
\text { hurt. Houses may be broken. }\end{array}$ \\
\hline 93 & 47 & girl & $\begin{array}{l}\text { Things would knock over like tables or } \\
\text { chairs. The bar stools might fall over } \\
\text { again. }\end{array}$ \\
\hline 94 & 55 & girl & He thinks he might be able to stop it. \\
\hline 95 & 58 & boy & $\begin{array}{l}\text { Glass may break, buildings may fall. The } \\
\text { electricity would go off. }\end{array}$ \\
\hline 96 & 37 & girl & $\begin{array}{l}\text { The electricity would go off. Glass would } \\
\text { break. }\end{array}$ \\
\hline 97 & 55 & girl & The glass would fall. \\
\hline 98 & 45 & boy & The earthquake would do it again. \\
\hline 99 & 58 & boy & The earth would bounce. \\
\hline 100 & 48 & & People might get hurt. \\
\hline 101 & 42 & girl & $\begin{array}{l}\text { The plants would sway and the house } \\
\text { would shake. }\end{array}$ \\
\hline 102 & 55 & boy & I don't know. \\
\hline 103 & 40 & boy & $\begin{array}{l}\text { Everything will be fall down and broken. } \\
\text { No electricity. }\end{array}$ \\
\hline
\end{tabular}


133

Appendix C continued

\begin{tabular}{llll}
\hline Subject & Age & Sex & Verbatim Answer \\
& & & \\
104 & 60 & boy & no response \\
105 & 36 & girl & The houses all shake. \\
106 & 52 & boy & The cupboard door would close. The \\
& & & $\begin{array}{l}\text { refrigerator door would swing open real } \\
\text { fast. }\end{array}$
\end{tabular}

Note. Ages are in months

Italics indicate parents' words 


\section{APPENDIX D}

Intensity of Reaction Scores 
Data Used for Calculating Intensity of Reaction Scores

$\begin{array}{cccccccccccccc}\text { Subject } & \text { Age } & \text { Sex } & \text { Q6 } & \text { Q7 } & \text { Q8 } & \text { Q9 } & \text { Q10 } & \text { Q11 } & 3 / 1 \mathrm{a} & 3 / 1 \mathrm{~b} & 3 / 1 \mathrm{c} & 3 / 2 \mathrm{C} & \text { Sco } \\ 21 & 38 & 2 & 0 & 0 & 0 & 0 & 0 & 0 & 1 & 1 & 1 & 1 & 4 \\ 31 & 36 & 1 & 0 & 0 & 0 & 0 & 0 & 0 & 1 & 1 & 1 & 1 & 4 \\ 37 & 51 & 1 & 0 & 0 & 0 & 0 & 0 & 0 & 1 & 1 & 1 & 1 & 4 \\ 45 & 42 & 2 & 0 & 0 & 0 & 0 & 0 & 0 & 1 & 1 & 1 & 1 & 4 \\ 57 & 58 & 2 & 0 & 0 & 0 & 0 & 0 & 0 & 1 & 1 & 1 & 1 & 4 \\ 68 & 42 & 2 & 0 & 0 & 0 & 0 & 0 & 0 & 1 & 1 & 1 & 1 & 4 \\ 72 & 42 & 2 & 0 & 0 & 0 & 0 & 0 & 0 & 1 & 1 & 1 & 1 & 4 \\ 82 & 62 & 1 & 0 & 0 & 0 & 0 & 0 & 0 & 1 & 1 & 1 & 1 & 4 \\ 89 & 42 & 1 & 0 & 0 & 0 & 0 & 0 & 0 & 1 & 1 & 1 & 1 & 4 \\ 97 & 55 & 2 & 0 & 0 & 0 & 0 & 0 & 0 & 1 & 1 & 1 & 1 & 4 \\ 100 & 48 & & 0 & 0 & 0 & 0 & 0 & 0 & 1 & 1 & 1 & 1 & 4 \\ 19 & 45 & 2 & 0 & 0 & 0 & 0 & 0 & 0 & 1 & 2 & 1 & 1 & 5 \\ 67 & 39 & 1 & 0 & 0 & 0 & 0 & 0 & 0 & 1 & 2 & 1 & 1 & 5 \\ 92 & 52 & 2 & 0 & 0 & 0 & 0 & 0 & 0 & 2 & 1 & 1 & 1 & 5 \\ 102 & 55 & 1 & 0 & 0 & 0 & 0 & 0 & 0 & 2 & 1 & 1 & 1 & 5 \\ 4 & 55 & 1 & 0 & 0 & 0 & 0 & 0 & 0 & 2 & 2 & 1 & 1 & 6 \\ 11 & 58 & 1 & 0 & 0 & 0 & 0 & 0 & 0 & 3 & 2 & 1 & 1 & 6 \\ 18 & 39 & 2 & 0 & 0 & 0 & 0 & 0 & 0 & 3 & 1 & 1 & 1 & 6 \\ 27 & 59 & 1 & 0 & 0 & 0 & 0 & 0 & 0 & 1 & 2 & 1 & 2 & 6 \\ 43 & 38 & 1 & 0 & 0 & 0 & 0 & 0 & 0 & 1 & 1 & 1 & 3 & 6 \\ 60 & 39 & 1 & 0 & 0 & 0 & 0 & 0 & 0 & 2 & 2 & 1 & 1 & 6 \\ 77 & 53 & & 0 & 0 & 0 & 0 & 0 & 0 & 2 & 1 & 1 & 2 & 6 \\ 90 & 49 & 1 & 0 & 0 & 0 & 0 & 0 & 0 & 2 & 1 & 1 & 2 & 6 \\ 94 & 57 & 1 & 0 & 0 & 0 & 0 & 0 & 0 & 2 & 1 & 1 & 2 & 6 \\ 98 & 45 & 1 & 0 & 0 & 0 & 0 & 0 & 0 & 2 & 2 & 1 & 1 & 6 \\ 35 & 51 & 1 & 0 & 0 & 0 & 1 & 0 & 0 & 1 & 3 & 1 & 1 & 7 \\ 81 & 47 & 2 & 0 & 0 & 0 & 0 & 0 & 0 & 3 & 1 & 1 & 2 & 7 \\ 99 & 58 & 1 & 0 & 0 & 0 & 0 & 0 & 0 & 4 & 1 & 1 & 1 & 7 \\ 9 & 48 & 2 & 0 & 0 & 0 & 0 & 0 & 0 & 3 & 2 & 1 & 2 & 8 \\ 85 & 58 & 2 & 0 & 0 & 1 & 0 & 0 & 0 & 4 & 1 & 1 & 1 & 8 \\ 103 & 40 & 1 & 0 & 0 & 4 & 0 & 0 & 0 & 1 & 1 & 1 & 1 & 8 \\ 105 & 36 & 2 & 0 & 0 & 1 & 1 & 0 & 0 & 2 & 1 & 1 & 2 & 8 \\ 29 & 59 & 1 & 1 & 0 & 0 & 0 & 0 & 0 & 3 & 2 & 1 & 2 & 9 \\ 47 & 53 & 1 & 0 & 1 & 0 & 0 & 0 & 0 & 3 & 2 & 1 & 2 & 9 \\ 84 & 55 & 1 & 0 & 0 & 0 & 0 & 0 & 1 & 2 & 2 & 2 & 2 & 9 \\ 5 & 56 & 1 & 1 & 0 & 0 & 0 & 0 & 0 & 2 & 2 & 1 & 4 & 10 \\ 12 & 48 & 1 & 0 & 0 & 0 & 0 & 0 & 0 & 4 & 1 & 1 & 4 & 10\end{array}$


$\begin{array}{lllllllllllll}\text { Subject Age Sex } & \text { Q6 } & \text { Q7 } & \text { Q8 } & \text { Q9 } & \text { Q10 } & \text { Q11 } & 3 / 1 \mathrm{a} & 3 / 1 \mathrm{~b} & 3 / 1 \mathrm{c} & 3 / 2 \mathrm{a} & \text { Sco }\end{array}$

$\begin{array}{clllllllllllll}17 & 38 & 2 & 1 & 1 & 1 & 0 & 0 & 0 & 3 & 2 & 1 & 1 & 10 \\ 39 & 57 & 1 & 0 & 0 & 4 & 1 & 0 & 0 & 2 & 1 & 1 & 1 & 10 \\ 65 & 36 & 2 & 0 & 0 & 1 & 1 & 0 & 0 & 3 & 2 & 1 & 2 & 10 \\ 66 & 50 & 1 & 0 & 0 & 1 & 1 & 0 & 0 & 3 & 2 & 1 & 2 & 10 \\ 96 & 37 & 2 & 1 & 0 & 0 & 0 & 0 & 0 & 4 & 1 & 1 & 3 & 10 \\ 48 & 63 & 1 & 0 & 0 & 0 & 0 & 0 & 0 & 3 & 3 & 2 & 3 & 11 \\ 54 & 52 & 1 & 1 & 0 & 1 & 0 & 0 & 0 & 4 & 2 & 1 & 2 & 11 \\ 62 & 61 & 1 & 0 & 0 & 0 & 3 & 0 & 0 & 3 & 2 & 1 & 2 & 11 \\ 75 & 50 & & 1 & 0 & 1 & 0 & 0 & 0 & 4 & 3 & 1 & 2 & 11 \\ 87 & 43 & 1 & 0 & 0 & 0 & 0 & 0 & 0 & 5 & 2 & 1 & 3 & 11 \\ 101 & 42 & 2 & 1 & 0 & 0 & 0 & 0 & 0 & 5 & 3 & 1 & 1 & 11 \\ 2 & 43 & 2 & 0 & 0 & 0 & 0 & 0 & 0 & 4 & 2 & 1 & 5 & 12 \\ 8 & 57 & 1 & 0 & 0 & 0 & 1 & 0 & 0 & 4 & 2 & 1 & 4 & 12 \\ 74 & 56 & 2 & 0 & 0 & 1 & 1 & 0 & 0 & 3 & 2 & 1 & 4 & 12 \\ 93 & 47 & 2 & 1 & 0 & 0 & 0 & 1 & 0 & 3 & 1 & 1 & 5 & 12 \\ 16 & 41 & 2 & 0 & 0 & 0 & 0 & 0 & 0 & 5 & 3 & 2 & 2 & 13 \\ 22 & 38 & 2 & 0 & 0 & 0 & 0 & 0 & 0 & 6 & 2 & 1 & 4 & 13 \\ 52 & 52 & 1 & 0 & 0 & 0 & 0 & 0 & 0 & 7 & 2 & 1 & 3 & 13 \\ 63 & 58 & 1 & 0 & 0 & 0 & 1 & 0 & 0 & 2 & 3 & 3 & 4 & 13 \\ 73 & 36 & 2 & 0 & 0 & 1 & 0 & 0 & 0 & 5 & 3 & 1 & 3 & 13 \\ 91 & 54 & 2 & 0 & 0 & 0 & 1 & 0 & 0 & 7 & 2 & 1 & 2 & 13 \\ 56 & 54 & 2 & 0 & 0 & 1 & 1 & 1 & 0 & 5 & 3 & 1 & 3 & 15 \\ 64 & 54 & 2 & 0 & 0 & 1 & 1 & 0 & 0 & 7 & 3 & 1 & 2 & 15 \\ 86 & 51 & 1 & 0 & 0 & 0 & 0 & 0 & 0 & 4 & 3 & 2 & 6 & 15 \\ 55 & 48 & 2 & 0 & 0 & 1 & 1 & 0 & 0 & 5 & 3 & 1 & 5 & 16 \\ 95 & 58 & 2 & 1 & 0 & 0 & 0 & 0 & 0 & 6 & 3 & 1 & 5 & 16 \\ 3 & 53 & 2 & 0 & 0 & 0 & 1 & 1 & 0 & 3 & 5 & 2 & 5 & 17 \\ 14 & 58 & 2 & 2 & 0 & 0 & 2 & 0 & 0 & 6 & 3 & 1 & 3 & 17 \\ 51 & 59 & 2 & 0 & 0 & 0 & 1 & 0 & 0 & 5 & 3 & 3 & 5 & 17 \\ 1 & 52 & 1 & 4 & 0 & 1 & 2 & 0 & 0 & 4 & 2 & 2 & 3 & 18 \\ 15 & 58 & 2 & 0 & 0 & 2 & 1 & 1 & 0 & 4 & 5 & 3 & 2 & 18 \\ 38 & 53 & 1 & 1 & 0 & 1 & 1 & 0 & 0 & 5 & 4 & 2 & 4 & 18 \\ 50 & 42 & 2 & 0 & 0 & 1 & 1 & 0 & 0 & 5 & 4 & 3 & 4 & 18 \\ 59 & 55 & 2 & 0 & 0 & 2 & 0 & 0 & 0 & 5 & 4 & 3 & 4 & 18 \\ 61 & 44 & 2 & 2 & 1 & 1 & 1 & 0 & 0 & 3 & 4 & 2 & 4 & 18 \\ 104 & 60 & 1 & 1 & 0 & 1 & 1 & 0 & 0 & 3 & 5 & 3 & 4 & 18 \\ 44 & 47 & 2 & 1 & 0 & 3 & 0 & 0 & 0 & 5 & 5 & 3 & 4 & 19 \\ 49 & 56 & 2 & 1 & 1 & 1 & 1 & 0 & 0 & 5 & 4 & 2 & 4 & 19 \\ 6 & 50 & 1 & 1 & 0 & 2 & 2 & 0 & 0 & 2 & 7 & 3 & 4 & 21 \\ 36 & 43 & 1 & 2 & 1 & 2 & 2 & 0 & 0 & 5 & 5 & 2 & 2 & 21\end{array}$




$\begin{array}{cccccccccccccc}\text { Subject } & \text { Age } & \text { Sex } & \text { Q6 } & \text { Q7 } & \text { Q8 } & \text { Q9 } & \text { Q10 } & \text { Q11 } & 3 / 1 a & 3 / 1 b & 3 / 1 c & 3 / 2 a & \text { Sco } \\ 13 & 40 & 2 & 0 & 0 & 3 & 2 & 0 & 0 & 6 & 4 & 2 & 5 & 22 \\ 30 & 64 & 1 & 1 & 0 & 2 & 1 & 0 & 0 & 6 & 4 & 3 & 5 & 22 \\ 83 & 36 & 2 & 3 & 0 & 2 & 1 & 0 & 0 & 6 & 4 & 3 & 3 & 22 \\ 20 & 44 & 1 & 1 & 1 & 0 & 0 & 0 & 0 & 7 & 5 & 2 & 7 & 23 \\ 23 & 60 & 2 & 1 & 0 & 2 & 1 & 0 & 0 & 6 & 3 & 7 & 3 & 23 \\ 34 & 58 & 1 & 2 & 0 & 2 & 1 & 0 & 0 & 3 & 6 & 3 & 6 & 23 \\ 58 & 57 & 1 & 1 & 0 & 1 & 1 & 0 & 0 & 6 & 4 & 3 & 7 & 23 \\ 88 & 55 & 2 & 0 & 0 & 1 & 1 & 0 & 0 & 7 & 5 & 2 & 7 & 23 \\ 46 & 47 & 1 & 1 & 0 & 2 & 3 & 0 & 0 & 6 & 5 & 4 & 3 & 24 \\ 32 & 45 & 2 & 3 & 0 & 4 & 3 & 0 & 0 & 2 & 4 & 6 & 3 & 25 \\ 71 & 47 & 2 & 2 & 0 & 2 & 3 & 1 & 1 & 7 & 4 & 3 & 2 & 25 \\ 41 & 43 & 1 & 4 & 0 & 3 & 2 & 0 & 0 & 4 & 6 & 6 & 1 & 26 \\ 69 & 49 & 2 & 1 & 0 & 0 & 1 & 0 & 0 & 4 & 7 & 6 & 7 & 26 \\ 76 & 53 & 2 & 4 & 0 & 1 & 1 & 0 & 0 & 4 & 7 & 4 & 3 & 26 \\ 24 & 60 & 2 & 1 & 0 & 2 & 2 & 0 & 0 & 7 & 5 & 5 & 5 & 27 \\ 42 & 60 & 2 & 3 & 0 & 3 & 0 & 0 & 0 & 5 & 7 & 4 & 5 & 27 \\ 78 & 51 & & 2 & 0 & 2 & 2 & 0 & 0 & 7 & 5 & 3 & 6 & 27 \\ 80 & 54 & 1 & 1 & 1 & 2 & 1 & 0 & 0 & 6 & 6 & 4 & 6 & 27 \\ 40 & 62 & 1 & 1 & 0 & 2 & 1 & 0 & 1 & 7 & 6 & 3 & 7 & 28 \\ 28 & 40 & 1 & 3 & 0 & 0 & 3 & 0 & 1 & 5 & 5 & 6 & 6 & 29 \\ 53 & 41 & 1 & 3 & 0 & 4 & 3 & 0 & 0 & 6 & 6 & 6 & 3 & 31 \\ 33 & 56 & 1 & 3 & 0 & 4 & 3 & 0 & 0 & 7 & 7 & 4 & 5 & 33 \\ 10 & 43 & 2 & 2 & 2 & 3 & 3 & 1 & 1 & 6 & 6 & 4 & 6 & 34 \\ 7 & 55 & 2 & 3 & 2 & 3 & 3 & 0 & 0 & 6 & 7 & 5 & 6 & 35 \\ 25 & 59 & 1 & 3 & 2 & 4 & 4 & 0 & 1 & 4 & 4 & 6 & 7 & 35 \\ 26 & 60 & 2 & 3 & 2 & 2 & 3 & 1 & 1 & 5 & 7 & 6 & 7 & 37 \\ 70 & 52 & 1 & 0 & 0 & 0 & 0 & 0 & 0 & & & & & \\ 79 & 54 & & 0 & 0 & 0 & 1 & 0 & 0 & & & & & \\ 106 & 43 & 1 & & & & & & & & & & & \end{array}$

Note. Ages are in months

Sex: 1=boy, 2=girl 